\title{
Wide-bandgap semiconductor materials: For their full bloom
}

\author{
$\operatorname{AUTHOR}(S)$ :
}

Fujita, Shizuo

CITATION:

Fujita, Shizuo. Wide-bandgap semiconductor materials: For their full bloom. Japanese Journal of Applied Physics 2015, 54(3): 030101.

\section{ISSUE DATE:}

2015-02-04

URL:

http://hdl.handle.net/2433/217690

\section{RIGHT:}

This is an author-created, un-copyedited version of an article accepted for publication in 'Japanese Journal of Applied Physics'. The publisher is not responsible for any errors or omissions in this version of the manuscript or any version derived from it. The Version of Record is available online at http://dx.doi.org/10.7567/JJAP.54.030101.; この論文は出版 社版でありません。引用の際には出版社版をご確認ご利用ください。; This is not the published version. Please cite only the published version. 


\section{Wide-bandgap semiconductor materials: For their full bloom ${ }^{\dagger}$}

\section{Shizuo Fujita}

Photonics and Electronics Science and Engineering Center, Kyoto University, Kyoto 615-8520, Japan

E-mail address: fujitasz@kuee.kyoto-u.ac.jp

\footnotetext{
${ }^{\dagger}$ This is a translated version of the original paper which appeared in Oyo Buturi 82 (2013) 836 [in Japanese].
}

Wide-bandgap semiconductors are expected to be applied to solid-state lighting and power devices, supporting a future energy-saving society. While GaN-based white LEDs have rapidly become widespread in the lighting industry, SiC-and GaN-based power devices have not yet achieved their popular use, like GaN-based white LEDs for lighting, despite having reached the practical phase. What are the issues to be addressed for such power devices? In addition, other wide-bandgap semiconductors such as diamond and oxides are attracting focusing interest due to their promising functions especially for power-device applications. There, however, should be many unknown phenomena and problems in their defect, surface, and interface properties, which must be addressed to fully exploit their functions. In this review, issues of wide-bandgap semiconductors to be addressed in their basic properties are examined toward their "full bloom".

\section{Introduction}

\subsection{From the dawn of compound semiconductors to wide-bandgap semiconductors}

Since the realization of GaAs bulk single-crystal substrates in 1954, researchers of compound semiconductors have strived toward research on new compound semiconductors, alloy semiconductors, heterostructures, and device applications by referring to the chart illustrating the 
relationship between the bandgap and lattice constant of zinc blende structures. ${ }^{1)}$ Since the late 1980s, an increasing number of researchers have focused on the potential of semiconductors with a wider bandgap as next-generation materials, expanding the range of research on semiconductors to include those with hexagonal and orthorhombic structures. Figure 1 shows the relationship between the energy bandgap and bond length for various compound semiconductors that are promising for practical application. Table I summarizes the basic physical properties of various wide-bandgap semiconductor single crystals, which are now attracting many researchers.

An increase in the bandgap leads to short-wavelength emission and an increased breakdown electric field. These have opened new application fields of wide-bandgap semiconductors to LEDs and laser diodes (LDs) from the visible and short (blue-green, blue, and UV) spectra range and to power devices supported by high breakdown field. ${ }^{9)}$

\subsection{Brief history and current status of development of wide-bandgap semiconductors}

In the late 1980s, group II-VI compounds, such as $\mathrm{ZnSe}$, were intensively focused on as wide-bandgap semiconductors. This was because alloy-crystal systems with such as $(\mathrm{Zn}, \mathrm{Mg}$, $\mathrm{Cd}$ ) and (Se, S), are lattice-matched to GaAs substrates, enabling the formation of heterojunctions that cover the blue-green to blue range, as shown in Fig. 1. Moreover, ZnSe substrates were developed and improved at this time. Although the development of ZnSe-based LDs with a wavelength of $\sim 500 \mathrm{~nm}$ was reported by many researchers, ${ }^{10-13)}$ further progress was little because of their short lifetime. Especially after the emergence of high-brightness GaN-based blue LEDs in $1993,{ }^{14)}$ the research on II-VI compounds had to be shrunk. However, many researchers who had "polished" their skills through research on group II-VI compounds shifted the target of their research to GaN-based optical devices, which greatly contributed to the subsequent progress of these devices. In addition, challenging research to address the issue of the short lifetime and develop green-to-yellow optical devices is still underway. ${ }^{15}$ 
On the other hand, in the 1980s and 1990s, marked progress had been seen for GaN toward practical blue LEDs with the evolution of extremely high-quality GaN epilayers on sapphire with low-temperature-grown AIN buffer layers, ${ }^{16)}$ p-type GaN by low-energy electron beam irradiation $(\mathrm{LEEBI})^{17)}$ or thermal annealing, ${ }^{18)}$ and high-quality InGaN layers. ${ }^{19)}$ The series of evolution was bloomed as high-brightness blue LEDs using InGaN/GaN heterostructure in 1993. ${ }^{14)}$ Rapid progress in crystal quality of $\mathrm{GaN}^{20)}$ was promptly followed by high-brightness green LEDs, ${ }^{21)}$ blue/UV LDs, ${ }^{22-25)}$ and white LEDs, ${ }^{25-27)}$ leading to the practical application of solid-state lighting ${ }^{28)}$ and high-density optical disks. GaN alloyed with AlN or InN has been making progress as a material that covers the visible to deep-UV range.

SiC has mainly been developed as a candidate for power devices. The invention of step-controlled epitaxy ${ }^{29,30)}$ was promptly followed by marked progress in its crystal quality and accelerated research toward practical devices. ${ }^{9,31-34)}$ Schottky-barrier diodes (SBDs) and metal-oxide-semiconductor field-effect transistors (MOSFETs) have already been the commercial stage, ${ }^{35)}$ demonstrating marked reduction in power consumption in railway and appliance applications.

Wide bandgap of GaN has also attracted focused attention as being applied to power devices. Two-dimensional electron gas formed at c-plane $\mathrm{AlGaN} / \mathrm{GaN}$ heterointerfaces by stress-induced polarization contributes as high electron mobility transistors (HEMTs) or heterojinction field-effect transistors (HFETs). ${ }^{35-38)}$ Their application targets are extending from high-frequency communication $^{39,40)}$ to electric power systems. As a power device material, diamond is also highly expected to achieve ultimate performance on the basis of its wider bandgap and higher thermal conductivity than those of the above materials. ${ }^{41-44)}$ 
Research on $\mathrm{ZnO}$ was accelerated in the $2000 \mathrm{~s}^{3,45)}$ and this material has been expected to be applied to UV LEDs owing to its high exciton binding energy of $60 \mathrm{meV}^{46}$ ) However, $\mathrm{ZnO}$ is not yet competitive because of the difficulty in forming reliable pn junctions and the marked progress of GaN-based LEDs. On the other hand, the research on $\mathrm{ZnO}$ has proven that oxides, which had not been considered for use as semiconductors before 1995, can be applied to semiconductor devices when prepared by appropriate techniques such as molecular beam epitaxy $(\mathrm{MBE}),{ }^{47-49)}$ triggering the subsequent advancement of research on various oxide semiconductor devices. $\mathrm{Ga}_{2} \mathrm{O}_{3}$ is one of examples and is being examined for application to deep-UV detectors $^{50,51)}$ and power devices ${ }^{7,52)}$ because its breakdown electric field is estimated to be higher than those of $\mathrm{SiC}$ and $\mathrm{GaN}$.

\subsection{Purpose of this review}

Currently, SiC- and GaN-based power devices are in the spotlight for their potential practical application and social impact. Nevertheless, they have not yet become as widespread as the white LEDs used for lighting. ${ }^{28)}$ It has often been heard that SiC-and GaN-based power devices are less advantageous over Si-based devices than expected owing to their high cost. Is this true?

A concern is that the characteristics of some SiC- and GaN-based power devices may change during operation owing to undefined physical phenomena and stress. The failure of power devices leads to a dangerous failure of the entire system wherein the power is uncontrollable. For devices that require high reliability, unknown or unexpected phenomena are fatal problems. To achieve the full bloom of SiC- and GaN-based power devices, it is necessary to clarify the physical processes in defects, the causes of deep energy levels, the factors affecting the carrier lifetime, and other basic physical properties of the materials. In-depth clarification of these fundamental properties is a task common with other wide-bandgap semiconductors, such as oxides and diamond, and will contribute to the realization of various applications highlighted by the 
characteristics of each material.

In this review, the current status of research on wide-bandgap semiconductors toward devices is summarized and the future direction of basic research required for their cutting-edge applications is discussed in order for their "full bloom" to solve the energy crisis which we should not be handed over to our descendants. Note that the focus of this article is only single-crystal materials rather than amorphous or polycrystalline composite oxides such as $\mathrm{InGaZnO}$.

\section{Future tasks for GaN-based optical devices}

\subsection{Current status of GaN-based optical devices}

Although GaN-based LEDs became widespread in market shortly after their emergence, their emission efficiency greatly depends on the emission peak wavelength. Figure 2 shows emission efficiencies (external quantum efficiencies) of LEDs with different wavelengths. ${ }^{53}$ The efficiency decreases at wavelengths of 500-600 nm (known as the "green gap") and suddenly decreases at wavelengths shorter than that corresponding to the bandgap of GaN (known as the "UV threshold"). Addressing these problems in order to realize LEDs with an efficiency of nearly $100 \%$ over a wide wavelength range is the ultimate goal for researchers of GaN-based LEDs.

\subsection{Task 1: Emission dynamics}

When the first blue LED was realized, researchers wondered why high-brightness emission was achieved despite the presence of dislocations with a density of $\sim 10^{9} \mathrm{~cm}^{-2}$ in the epilayer. This was later attributed to the emission of excitons localized at deep potential regions, rather than the nonradiative recombination of carriers in defects, as a result of composition fluctuation in the InGaN emission layer. ${ }^{54)}$ Thus, the emission mechanism of GaN-based LEDs includes physical phenomena different from those in traditional III-V compound semiconductors. The clarification 
of these phenomena has significantly contributed to the improved emission efficiency and reliability.

For InGaN-based LEDs, the emission efficiency decreases with increasing current density, which is known as the efficiency droop. ${ }^{55,56)}$ This hampers high-brightness emission, and therefore research to clarify its causes has eagerly been carried out. In particular, a model in which Auger recombination is assumed to be the main cause of nonradiative recombination at high current densities has attracted attention. ${ }^{57-59)}$ However, Kawakami ${ }^{60)}$ and Amano ${ }^{61)}$ pointed out the drawbacks of this model on the basis of their deep investigation on the emission dynamics. Moreover, the efficiency droop is less in LEDs with a reduced number of defects fabricated on GaN substrates, ${ }^{62)}$ suggesting any physics and mechanisms different from simple Auger recombination associating the efficiency droop.

Kaneta et al. ${ }^{63-65)}$ clarified the correlation between the effect of exciton localization and defects in an ultrasmall region using a scanning near-field optical microscope (SNOM). Compared to cathodoluminescence (CL) technique, special resolution of investigation can be markedly narrowed by using a SNOM, as shown in the top figure of Fig. $3,{ }^{63)}$ typically $<100 \mathrm{~nm}$. They showed that (i) in the violet-emitting quantum well (QW), shallow localized states enhance carrier diffusion and photoluminescence (PL) intensity mapping is well correlated with threading dislocation (TD) distribution [Fig. 3(a)], (ii) In the blue-emitting QW, deep localized states confine carriers and avoid non-radiative recombination in TDs [Fig. 3(b)], and (iii) in the green-emitting QW, TDs are formed in localized states and cause enhanced trapping of carriers, markedly reducing internal quantum efficiency [Fig. 3(c)]. Later they developed a dual-probe SNOM, ${ }^{64)}$ and visualized the more detailed processes of carrier motion in space. ${ }^{65)}$ Photodynamics research on such ultrasmall regions will greatly contribute to improving the efficiency of LEDs and LDs in the future. 


\subsection{Task 2: Short-wavelength LEDs}

LEDs with a wavelength shorter than the UV threshold have an AlGaN active layer and require a wider-bandgap cladding layer. In this case, there are three problems: (1) the threading dislocation density in the AlGaN active layer is high, (2) the fabrication of p-type AlGaN layers is difficult, and (3) the light extraction efficiency is low because of light absorption by the p-contact layer and electrodes. ${ }^{66)}$ To address problem (1), efforts has been concentrated on reducing the threading dislocation density of AIN buffer layers on sapphire substrates. ${ }^{67,68)}$ Problem (2) is difficult to address because of the high activation energy of $\mathrm{Mg}$ as an acceptor $\left(630 \mathrm{meV}^{69)}\right.$ in AlN). The formation of a barrier layer against electrons has been attempted to assist the effective transfer of holes into the emission layer. ${ }^{70)}$ No decisive solution to problem (3) has yet been found, and the light extraction efficiency is only approximately $8 \%$ for deep-UV LEDs. ${ }^{66}$ In addition, there has been an attempt to utilize the effect of In localization, as observed in $\operatorname{InGaN},{ }^{54)}$ by doping In into an active layer to form an InAlGaN layer. ${ }^{71)}$ Owing to these attempts, the efficiency of deep-UV to UV LEDs has been improved, as shown in Fig. $4,{ }^{66}$ but has not yet reached the level of blue LEDs. Further basic research is needed to clarify the emission dynamics in the InAlGaN emission layer and develop some technologies of forming contacts to p-type layers.

Currently, the development of AIN substrates is being accelerated because problem (1) can be solved using AIN substrates. ${ }^{72,73)}$ Advantages of using AlN substrates have been proved by the growth of high-quality AIN epilayers on AIN substrates ${ }^{74)}$ and photoexcited laser oscillation using AlGaN/AIN quantum wells. ${ }^{75)}$ Further progress of AlN substrates is expected in the future.

Meanwhile, there has been an attempt to realize deep-UV emission from AlGaN/AIN quantum wells pumped by an electron beam without forming pn junctions. A power efficiency of $40 \%$ and a device output of $100 \mathrm{~mW}$ have been achieved for a wavelength of $240 \mathrm{~nm}^{76}$ ) 


\subsection{Task 3: GaN substrates}

To obtain ultrahigh-brightness white LEDs, a high current density is required to drive the LEDs, and hence, the series resistance of the LEDs must be sufficiently reduced. Vertical LEDs using conductive substrates are preferred for this purpose, and GaN substrates are ideal. Although GaN substrates have been used for LDs, large GaN substrates have not yet been fabricated and the fabrication cost of GaN substrates is high. However, the development of GaN substrates has been accelerated in response to the recent progress of GaN-based power devices ${ }^{45}$, and a high-brightness LED with a luminous efficacy of $200 \mathrm{~lm} / \mathrm{W}$ has been achieved. ${ }^{77)}$ The current status and tasks for GaN substrates, including their application to power devices, will be described later.

\subsection{Other tasks}

Lighting applications will be a future major goal for GaN-based optical devices. In this case, the improvement of their color-rendering properties is essential and the devices are expected to be studied as a system integrated with appropriate phosphors and LEDs with different wavelengths. Recently, Philips reported the successful development of a lamp with a luminous efficacy of 200 $\mathrm{lm} / \mathrm{W}$ and high color-rendering properties that can replace fluorescent lamps. ${ }^{78)}$

\section{Future tasks for SiC-based power devices}

\subsection{Current status of $\mathrm{SiC}$-based power devices}

SiC-based power devices have been making remarkable progress in response to the commercialization of epitaxial growth systems and the reduction in the cost of large $\mathrm{SiC}$ substrates with low defect densities. SiC-based SBDs are already in the phase of mass production and 1700 V/75 A devices are in the research and development phase. ${ }^{79)}$ MOSFETs now have improved control of the interface between the gate insulating film and the $\mathrm{SiC}$ substrate ${ }^{80)}$ and are in the 
practical phase. ${ }^{81)}$

On the other hand, pin diodes, which are one of bipolar devices, have the advantage that the on-resistance can be reduced by injecting carriers into the i-layer and therefore they are attractive as practical devices with an ultrahigh breakdown voltage. Kimoto and co-workers realized pin diodes with a breakdown voltage of $21.7 \mathrm{kV}$ by reducing the deep levels in $\mathrm{SiC}$ and adopting a structure that suppressed the electric-field concentration within the device. ${ }^{82,83)}$ The suppression of defects is also a high-priority task for the progress of bipolar junction transistors (BJTs). ${ }^{84,85)}$

The validity of SiC-based power devices has been demonstrated for use in modules for controlling the power of indoor air conditioners ${ }^{86}$ and inverter systems for railway cars. ${ }^{87}$ Power semiconductor modules have also already been commercialized. ${ }^{88)}$ Full-power modules using SiC MOSFETs are in the phase of mass production. ${ }^{89)}$

\subsection{Task 1: Defects in substrates and epilayers}

Since power devices have a large area to carry a large current, the defect density greatly affects the yield and the defects are considered to be device killers. Denoting the defect density as $D\left(\mathrm{~cm}^{-2}\right)$ and the device area as $A\left(\mathrm{~cm}^{2}\right)$, the yield of a device is expressed by $Y=\exp (-D A)$, as shown in Fig. $5^{90)}$ For $\sim 10$-A-class devices, a defect density of $\leq 10 \mathrm{~cm}^{-2}$ is required to achieve a yield of $80 \%$. However, future 100-A-class devices will require a defect density of $\leq 0.1 \mathrm{~cm}^{-2}$.

Table II summarizes the type and density of defects in currently available SiC and their effect on decreasing the breakdown voltage. ${ }^{90)}$ Micropipes greatly affect device performance but have recently been eliminated to a negligible level. In contrast, threading spiral dislocations (TSDs), threading edge dislocations (TEDs), and basal plane dislocations (BPDs) still remain at high densities, although their effects on the breakdown voltage are not fatal. Figure 6 schematically 
shows defects in a SiC substrate and how they propagate to the epilayer. Almost all of TSDs and TEDs propagate from the substrate to the epilayer. The majority of BPDs do not propagate to the epilayer but approximately $10 \%$ do. ${ }^{91,92)}$ BPDs that have propagated to the epilayer expand upon the application of forward current in bipolar devices while forming stacking faults, causing the serious problem of deterioration of the forward characteristics of the devices. ${ }^{93)}$ Hence, the propagation of BPDs from the substrate to the epilayer should be avoided. ${ }^{94-96)}$ There are still many unclear points in the behavior and control of the above defects, and they are important issues to be addressed in order to improve device performance in the future. For details, readers are referred to Ref. 97.

\subsection{Task 2: Insulator/SiC interfaces}

The characteristic of insulator/semiconductor interfaces is key in the realization of SiC MOSFETs. When $\mathrm{SiC}$ substrates are used, $\mathrm{a} \mathrm{SiO}_{2}$ layer is easily formed by thermal oxidation; however, the interface state density was incredibly high for SiC-based devices introduced in 2000 and the channel mobility was two orders of magnitude lower than the bulk mobility. ${ }^{98-102)}$ To overcome this problem, researchers changed the plane orientation ${ }^{103-105)}$ and the conditions for fabricating oxide layers, ${ }^{106-108)}$ achieving a channel mobility exceeding $100 \mathrm{~cm}^{2} /$ Vs. Meanwhile, the fluctuation in threshold voltage $\left(V_{\mathrm{TH}}\right)$ is another problem, ${ }^{109-116)}$ which may somewhat be associated with issues on channel mobility. Figure 7 shows the capacitance-voltage hysteresis reported by Okamoto et al. ${ }^{117)}$ for a $4 \mathrm{H}-\mathrm{SiC}$ C-face MOS capacitor processed by wet oxidation. The variation in hysteresis suggests existence of various types of traps, for which we should overcome in order to realize an excellent MOS structure. $\mathrm{H}_{2}$ postoxidation annealing (POA) ${ }^{117)}$ and phosphosilicate glass (PSG)/SiO 2 double structure ${ }^{118)}$ are examples effective to realize simultaneously high channel mobility and low threshold voltage instability. Moreover, it was shown that the use of $\mathrm{AlON}$ as a gate insulator increased the breakdown voltage and reduced the leakage current. ${ }^{83)}$ Although SiC MOSFETs have reached the practical phase, ${ }^{89)}$ the interface still 
has a large effect on device performance, and it is an essential task to clarify the physical phenomena at the interface. ${ }^{119)}$

\subsection{Task 3: Carrier lifetime and deep levels}

Future $\mathrm{SiC}$ bipolar devices (e.g., pin diodes, BJTs) are expected to have high voltage and current capabilities. Carrier lifetime is a key physical parameter for these devices because the behavior of minority carriers determines the device performance. For bipolar devices with a breakdown voltage of $20 \mathrm{kV}$, the necessary carrier lifetime is estimated to be $\geq 15 \mu$ s. $^{120}$ ) However, an excessively long lifetime worsens the switching performance. Hence, devices should be designed to have an appropriate carrier lifetime in accordance with their purposes.

In $\sim 2000$, the carrier lifetime of $\mathrm{SiC}$ was only $\leq 1 \mu \mathrm{s}$, even though it was an indirect transition semiconductor. ${ }^{121)}$ This value is too small and was attributed to the presence of lifetime-killing defects, that is, carrier recombination centers. Among the point defects in $\mathrm{SiC}$, the $Z_{1 / 2}$ centers at $E_{\mathrm{c}}-0.65 \mathrm{eV}$ are known to act as effective lifetime killers. ${ }^{122-124)}$ With the reduction of the concentration of $Z_{1 / 2}$ centers by optimization of the growth conditions, ${ }^{125)}$ carbon implantation and annealing, ${ }^{126}$ and thermal oxidation, ${ }^{127)}$ a longer lifetime of $20-30 \mu$ s has recently been achieved. ${ }^{128,129)}$ A report also showed that a lifetime appropriate for the device can be achieved by controlling the concentration of $Z_{1 / 2}$ centers through electron beam irradiation and thermal treatment. $^{124)}$

Many of the above studies concern n-type SiC. Although the improvement ${ }^{130)}$ and control ${ }^{131)}$ of the carrier lifetime in p-type $\mathrm{SiC}$ were reported by Hayashi and co-workers, the mechanism of lifetime killers is complicated and the effect of deep levels on the carrier lifetime remains unclear. Thus, controlling the carrier lifetime is essential for achieving future improvements in bipolar devices. It is necessary to clarify the physical factors limiting the carrier lifetime and develop 
processing techniques on the basis of these factors.

\subsection{Other tasks}

Many of the physical parameters of SiC have remained unclear and information needed to accurately simulate SiC-based devices is not available. Moreover, there are many issues concerning the fabrication processes for SiC-based devices. For example, high-temperature ion implantation and thermal treatment are required to locally control the conductivity, but these processes may cause defects. The development of new processes is also required in addition to the clarification of these issues. Technology of forming good ohmic electrodes should also be improved. $^{132)}$

\section{Future tasks for GaN-based power devices}

\subsection{Current status of GaN-based power devices}

Currently, GaN-based power devices are mainly fabricated by growing heteroepitaxial layers on $\mathrm{Si}$ substrates because large $\mathrm{GaN}$ substrates have been under the development stage. Attempts have been made to fabricate $\mathrm{GaN}$ devices on $\mathrm{SiC}$ substrates, but the use of $\mathrm{Si}$ substrates is far advantageous in terms of cost reduction for large substrates. However, many defects are likely to thread through the GaN layers and to cause excessive leakage. This may deteriorate performance of devices that carry current in the vertical direction. Therefore, attentions are focused on lateral-structure devices such as HEMTs and HFETs, which use the lateral conduction of a two-dimensional electron gas that is induced by the polarization of $\mathrm{AlGaN} / \mathrm{GaN}$ heterointerfaces. With this device configuration, GaN has been practically applied to high-frequency power devices for rapid operation before being applied to power devices with high-voltage and -current capabilities. $^{133-135)}$

GaN-based devices are basically normally-on because the formation of a two-dimensional electron 
gas is caused by spontaneous polarization. For use as power devices, however, they must be normally-off (not conduct current in the normal state) and also have high current capability and low on-resistance. ${ }^{136,137)}$

Recently, GaN-based devices with a breakdown voltage of $600 \mathrm{~V}$ have been reported, ${ }^{138,139)}$ and the validity of power conditioners equipped with GaN-based devices has also been demonstrated. ${ }^{140)}$ In addition, vertical pn-junction diodes and with a breakdown voltage of $\geq 3 \mathrm{kV}$ using a GaN substrate have been reported. ${ }^{141)}$

\subsection{Task 1: Reliability}

GaN-based power devices have the problem of unstable performance, which decreases their reliability. The greatest concern is current collapse, in which the drain current decreases owing to the gate voltage stress. ${ }^{142-145)}$ Such instability is considered to be due to the combination and release of carriers via traps. Researchers have attempted to address this problem by reducing surface levels through surface passivation ${ }^{146}$ or by thickening the epilayer and inserting a field plate (FP) to suppress the electric field between the gate and the drain, ${ }^{14-149)}$ as shown in Fig. $8 .{ }^{147)}$ Ohno pointed out that the general Shockley-Read-Hall (SRH) model is unable to explain the causes of current collapse. ${ }^{150)}$ The physical mechanism of current collapse has not yet been sufficiently clarified, and further research is needed to elucidate its mechanism and develop control techniques in the future.

It has been pointed out that GaN-based power devices have many other problems related to their reliability, such as unstable on-resistance and leakage current. ${ }^{151,152)}$ Many stacking faults are present in the $\mathrm{GaN}$ layers on $\mathrm{Si}$ substrates and are likely to contribute to unstable device performance. Various basic studies are needed for GaN-based power devices to fully bloom. 


\subsection{Task 2: Normally-off devices}

Various attempts have been made to achieve normally-off GaN FETs. ${ }^{136,137)}$ Figure 9 (a)-(e) ${ }^{153)}$ schematically shows the achievements. In these attempts, however, new traps were generated, causing a shift in $V_{\mathrm{TH}}{ }^{137)}$ Although new structures will be proposed in the future, researchers should be careful to recognize demerits that may underlie apparent advantages. Recently, MOS-HFET ${ }^{39)}$ and gate injection transistor $(\mathrm{GIT})^{40)}$ are recognized to be two of the most promising structures, which are illustrated in Fig. 10(a) and (b), respectively.

\subsection{Task 3: GaN substrates}

Marked efforts and progress have been carried out for GaN substrates. ${ }^{154)}$ A practical method of growing GaN substrates is hydride vapor phase epitaxy (HVPE). ${ }^{155-158)}$ As liquid-phase growth methods, the high-temperature high-pressure method, ${ }^{159,160)}$ the ammonothermal method, ${ }^{161-163)}$ and the Na flux method ${ }^{164-167)}$ have been studied for GaN substrates. The dislocation densities have been reported to be $5 \times 10^{7} \mathrm{~cm}^{-2}$ for the HVPE method ${ }^{158)}$ and $10^{3}-10^{5} \mathrm{~cm}^{-2}$ for the Na flux method, ${ }^{165-167)}$ meaning that epilayers with a dislocation density lower than that in GaN/Si (approximately $10^{8}-10^{9} \mathrm{~cm}^{-2}$ ) can be obtained. The fabrication cost is a concern but the effect of dislocations remaining in the substrates must also be considered. The dislocation density of GaN substrates is not yet competitive with that of $\mathrm{SiC}$ substrates, and findings on the behavior of dislocations are limited because of the small number of experiments on homoepitaxial growth. GaN substrates should be further studied to improve their quality and clarify the mechanism underlying the propagation of dislocations during epitaxial growth and their effect on devices.

\subsection{Other tasks}

Similarly to SiC, GaN still has many unclear physical parameters, such as the breakdown electric field. Device simulation is indispensable for designing device structures and FPs to avoid the effect of current collapse. Research on such physical parameters should be promoted. 


\section{Future trends of diamond-based and gallium-oxide-based devices}

\subsection{Current status and tasks for diamond-based devices}

Diamond has the potential to realize power devices with the ultimate performance of fast operation at high temperatures with low loss and a high breakdown voltage. ${ }^{41)}$ Previously, many studies were in the stage of material exploration. However, the rapid low-loss switching performance of SBDs ${ }^{168)}$ and junction FETs (JFETs) with a low leakage current ${ }^{169)}$ have recently been reported, indicating the possibility of applying diamond to small semiconductor power devices.

However, there are still many unknown issues concerning the device application of diamond, which has basic problems such as the difficulty of n-type doping, deep donor levels, and a low activation rate. Although $\mathrm{P}^{170-172)}$ and $\mathrm{As}^{173)}$ doping have been attempted to obtain n-type diamond layers, more research on the physical properties of diamond is needed in the future. Interestingly, diamond exhibits superconductivity upon B doping. ${ }^{174)}$ Anyhow, diamond is highly attractive to materials researchers and may lead to unprecedented novel devices.

A major hurdle in the practical application of diamond devices is the substrate, which is discussed in detail in Ref. 41. As shown in Table III, diamond substrates have many defects and their behavior, propagation to epilayers, and effects on electrical characteristics and reliability remain unclear. These issues must be addressed in future studies.

\subsection{Current status and tasks for $\mathrm{Ga}_{2} \mathrm{O}_{3}$-based devices}

$\mathrm{Ga}_{2} \mathrm{O}_{3}$ has recently attracted attention as a fourth-generation semiconductor material that can be used for power devices. As shown in Table $\mathrm{I}_{,} \mathrm{Ga}_{2} \mathrm{O}_{3}$ has a bandgap wider than those of $\mathrm{SiC}$ and $\mathrm{GaN}$. Hence, $\mathrm{Ga}_{2} \mathrm{O}_{3}$ is expected to have a high breakdown electric field and a low on-resistance $R_{\mathrm{on}}$, which may be estimated by the well-known formula of $R_{\mathrm{on}}=4 V_{\mathrm{B}}^{2} / \varepsilon \mu_{\mathrm{n}} E_{\mathrm{B}}{ }^{3}$, where $V_{\mathrm{B}}, \varepsilon, \mu_{\mathrm{n}}$, 
and $E_{\mathrm{B}}$ denote the breakdown voltage, the permittivity, the electron mobility, and the breakdown electric field, respectively. Moreover, $\mathrm{Ga}_{2} \mathrm{O}_{3}$ substrates can be fabricated by a solution method similar to that used to grow sapphire substrates. ${ }^{175-179)}$

Sasaki et al. fabricated $\mathrm{Ga}_{2} \mathrm{O}_{3}$ homoepitaxial layers by $\mathrm{MBE}$ using ozone as an oxygen source and controlled n-type conduction to within the range of $10^{16}-10^{19} \mathrm{~cm}^{-3}$ by $\mathrm{Sn}$ doping to obtain a prototype Pt SBD. ${ }^{52)}$ Higashiwaki et al. fabricated MESFETs ${ }^{7)}$ and then MOSFETs operating even at a high temperature of $250^{\circ} \mathrm{C},{ }^{180)}$ revealing the advantages of $\mathrm{Ga}_{2} \mathrm{O}_{3}$ for use in electron devices.

The author has engaged in research on $\mathrm{Ga}_{2} \mathrm{O}_{3}$ and sincerely wishes that this material is fully applied to power devices. It is too early to discuss the superiority of $\mathrm{Ga}_{2} \mathrm{O}_{3}$ over $\mathrm{SiC}$ and $\mathrm{GaN}$, but it is an apparent advantage of $\mathrm{Ga}_{2} \mathrm{O}_{3}$ that coherent heterostructures are formed ${ }^{181)}$ and its conductivity can be controlled by ion implantation ${ }^{182)}$ and thermal treatment. ${ }^{183,184)}$ However, the issues concerning $\mathrm{Ga}_{2} \mathrm{O}_{3}$ are wide-ranging and include substrates, crystal growth, control of material properties, device processes, and implementation techniques for improving thermal conductivity. The establishment of a strong collaborative research system supported by the government will greatly accelerate the development of original $\mathrm{Ga}_{2} \mathrm{O}_{3}$-related technologies.

Currently, the p-type doping of $\mathrm{Ga}_{2} \mathrm{O}_{3}$ is not firmly established, and this issue must eventually be addressed in the future. The replacement of Ga with $\mathrm{Mg}$ or $\mathrm{Zn}$ (known as cation replacement common to $\mathrm{GaN}$ ) may be possible rather than anion replacement in $\mathrm{ZnO}$ (doping $\mathrm{N}$ ), and actually high-resistivity substrates have been shown by Mg doping. ${ }^{7)}$ Therefore, the advancement of these doping techniques is desired. If $\mathrm{p}$-type $\mathrm{Ga}_{2} \mathrm{O}_{3}$ is obtained, not only vertical power devices but also deep UV LEDs ${ }^{185)}$ will be advanced. 
There has also been an attempt to use $\mathrm{Ga}_{2} \mathrm{O}_{3}$ substrates for GaN-based LEDs on the basis of the fact that the substrates have a low resistance and wide bandgap. ${ }^{186-188)}$

\section{Wide-bandgap oxide semiconductors}

As 2-inch $\mathrm{ZnO}$ substrates have become commercially available, $\mathrm{ZnO}$ is expected to be applied to UV LEDs but research has not yet reached the practical level. Future high-priority tasks concerning $\mathrm{ZnO}$ include the formation of stable pn junctions and other basic materials research. ${ }^{46}$ ) In the field of crystal growth, advanced control of the $\mathrm{MgZnO}$ composition and $\mathrm{MgZnO} / \mathrm{ZnO}$ interfaces has been achieved, ${ }^{189,190)}$ leading to the creation of new spin-related properties. ${ }^{191,192)}$

In addition to $\mathrm{ZnO}$ and $\mathrm{Ga}_{2} \mathrm{O}_{3}$, other wide-bandgap oxide semiconductors, for example, $\mathrm{SnO}_{2}$, ${ }^{193-}$ ${ }^{195)} \mathrm{NiO},{ }^{196)} \mathrm{Cu}_{2} \mathrm{O},{ }^{197)}$ corundum $\mathrm{Ga}_{2} \mathrm{O}_{3}\left(\alpha-\mathrm{Ga}_{2} \mathrm{O}_{3}\right),{ }^{198)}$ and $\alpha-\mathrm{In}_{2} \mathrm{O}_{3},{ }^{199)}$ have attracted attention in terms of functions, and research toward realizing their future device applications is ongoing. Moreover, some researchers have attempted to form alloy crystals of semiconductors and transition-metal oxides with different functions to derive new functions. ${ }^{200,201)}$ Oxides have various functions and are expected to be applied to devices by adopting new principles revealed by the progress of in-depth research on their properties.

\section{Is a substrate a key issue?*}

In the evolution of III-V alloy semiconductors, such as AlGaInP and InGaAsP, the development of substrates preceded the growth of crystals, and there was the well-established theory that even a slight lattice mismatch between the substrate and the epilayer greatly affects the crystal quality. ${ }^{202)}$ In contrast, for wide-bandgap semiconductors, researchers were interested in the properties of materials and tackled the development of small substrates and the exploration of material

\footnotetext{
* In Japanese, the same word of "kiban" is used both for "substrate" and "key issue" though their Chinese characters are different. In an original publication in Japanese, the author intended to claim that "substrate (kiban)" and "key issue (kiban)" are the equivalent words.
} 
properties of heteroepitaxial layers in parallel. Research on SiC aiming at device applications was carried out using Si substrates before the development of SiC substrates. ${ }^{203,204)}$ Although ZnSe layers were heteroepitaxially grown on GaAs substrates, strict lattice matching was required between the substrates and the epilayers, ${ }^{205,206)}$ and the development of ZnSe substrates was carried out to meet this requirement. ${ }^{207)}$ What the history tells us is that researchers have continuously aimed to develop high-quality substrates as the basis of device applications. Although large SiC and GaN substrates have gradually been obtained, defects in these substrates are not negligible and the uniformity of quality is questionable. Epilayers are considered to take over any problems of substrates in some form. Complete understanding and control of the properties of substrates and the behavior of their defects will be a fundamental technology for future device applications for various wide-bandgap semiconductor materials, not just $\mathrm{SiC}$ and $\mathrm{GaN}$.

\section{Final remarks}

In this review, the issues to be addressed in order for wide-bandgap semiconductors to fully bloom are summarized and the importance of basic research facing to the current status of their research and applications is emphasized. Wide-bandgap semiconductors still have the problems of unsatisfactory yield and reliability, whereas power devices have reached the stage of mass production. Such problems are sometimes attributed to production technologies, but production technologies may sometimes be treated as confidential. We should recognize that wide-bandgap semiconductors still have many unclear physical phenomena, which can be elucidated not by simply optimizing production technologies but by careful investigation of basic physics by specialists. I hope that these noteworthy materials will fully bloom through open discussions that take into account their basic properties.

After the publication of the original version of this article in Oyo Buturi in 2013, progress of wide-bandgap semiconductors has been accelerated. ${ }^{208-210)}$ Commercial applications of 
SiC-based power devices have been further expanded to wide area including railway cars ${ }^{211)}$, where full-SiC inverters can reduce the train operation power by $20-36 \%$, air conditioners, and power conditioners in photovoltaic systems, together with commercialization of power modules of improved efficiency and compact configuration. ${ }^{212)}$ Achievements of high-quality $\mathrm{SiO}_{2} / \mathrm{SiC}$ interface with the interface state density of as low as $<10^{11} \mathrm{~cm}^{-2} \mathrm{eV}^{-1213)}$ is a good news supporting evolution of MOSFETs, while understanding of the breakdown phenomena has been advanced. ${ }^{214)}$ Progress of GaN-based power devices is also noteworthy supported by high quality GaN substrates as well as large area GaN/Si structures. A vertical MOSFET with $1.6 \mathrm{kV}$ blocking voltage on a free standing GaN substrate ${ }^{215)}$ and normally-off lateral MOSFET with $825 \mathrm{~V}$ breakdown voltage on an 8 -inch $\mathrm{Si}$ wafer $^{216}$ are typical examples. Diamond vertical SBD realized forward currents and blocking voltages of more than $1 \mathrm{~A}$ and $300 \mathrm{~V}$ at $250{ }^{\circ} \mathrm{C} .{ }^{217}$ ) Exploration of LED resulted in first demonstration of an InGaN-based red LED emitting $629 \mathrm{~nm}$ with the light output power exceeding $1 \mathrm{~mW}$ at $20 \mathrm{~mA},{ }^{218)}$ as well as steady development of high-power white LEDs. ${ }^{219)}$ It was an exciting news that Profs. Isamu Akasaki, Hiroshi Amano, and Shuji Nakamura were awarded the 2014 Nobel Prize in Physics for the development of efficient blue GaN LEDs. ${ }^{220)}$ For $\mathrm{Ga}_{2} \mathrm{O}_{3}$, detailed understandings of the growth processes ${ }^{221,222)}$ and $\mathrm{Al}_{2} \mathrm{O}_{3} / \mathrm{Ga}_{2} \mathrm{O}_{3}$ interface properties ${ }^{223)}$ have been progressed. Novel use of wide-bandgap oxides such as $\alpha-\mathrm{Fe}_{2} \mathrm{O}_{3}$ for solar calls ${ }^{224)}$ and $\alpha-(\mathrm{GaFe})_{2} \mathrm{O}_{3}$ for spintronic applications ${ }^{225)}$ was demonstrated. Together with the development of alloy semiconductors ${ }^{226)}$, oxide semiconductors may open new application fields not limited to power devices. We can really feel that wide-bandgap semiconductors are firmly directing to their full bloom being supported by the devotion of researchers for physics in there.

\section{Acknowledgements}

The author sincerely thanks the researchers of wide-bandgap semiconductor communities for their valuable advice and suggestions in their respective fields. Thanks to their first-hand opinions 
based on the state-of-the-art research and development of materials that are currently rapidly making progress, the author obtained enough supplementary knowledge to compile a review article that reflects the current status of wide-bandgap semiconductors. In particular, researchers at Kyoto University provided me with very meaningful findings through close daily contact. The author wishes to express his gratitude to the many experts who supported him in writing this article. Finally, the author thanks Norio Suzuki at my laboratory for preparing Fig. 1.

\section{References}

1) A. Sasaki, M. Nishiuma, and Y. Takeda, Jpn. J. Appl. Phys. 19, 1695 (1980).

2) C. Buttay, D. Planson, B. Allard, D. Bergogne, P. Bevilacqua, C. Joubert, M. Lazar, C. Martin, H. Morel, D. Tournier, and C. Raynaud, Mat. Sci. Eng. B 176, 283 (2011).

3) Ü. Özgür, Ya. I. Alivov, C. Liu, A. Teke, M. A. Reshchikov, S. Doğan, V. Avrutin, S.-J. Cho, and H. Morkoç, J. Appl. Phys. 98, 041301 (2005).

4) J. D. Albrecht, P. P. Ruden, S. Limpijumnong, W. R. L. Lambrecht, and K. F. Brennan, J. Appl. Phys. 86, 6864 (1999).

5) M. Orita, H. Ohta, M. Hirano, and H. Hosono, Appl. Phys. Lett. 77, 4166 (2000)..

6) K. Yamaguchi, Solid-St. Commun. 131, 739 (2004).

7) M. Higashiwaki, K. Sasaki, A. Kuramata, T. Masui, and S. Yamakoshi, Appl. Phys. Lett. 100, 013504 (2012)

8) $\mathrm{Ga}_{2} \mathrm{O} 3$ substrate catalog, Tamura Corporation.

9) H. Morkoç S. Strite, G.B. Gao, M.E. Lin, B. Sverdlov, and M. Burns, J. Appl. Phys. 76, 1363 (1994).

10) M. A. Haase, J. Qiu, J. M. DePuydt, and H. Cheng, Appl. Phys. Lett. 59, 1272 (1991).

11) H. Jeon, J. Ding, W. Patterson, A. V. Nurmikko, W. Xie, D. C. Grillo, M. Kobayashi, and R. L. Gunshor, Appl. Phys. Lett. 59, 3619(1991).

12) S. Itoh, N. Nakayama, T. Ohata, M. Ozawa, H. Okuyama, K. Nakano, A. Ishibashi, M. Ikeda, and Y. Mori, Jpn. J. Appl. Phys. 32, L1530 (1993). 
13) S. Itoh, N. Nakayama, T. Ohata, M. Ozawa, H. Okuyama, K. Nakano, M. Ikeda, A. Ishibashi, and Y. Mori, Jpn. J. Appl. Phys. 33, L639 (1994).

14) S. Nakamura, T. Mukai, and M. Senoh, Appl. Phys. Lett. 64, 1687 (1994); press-released in December 1993.

15) J. Kasai, R. Akimoto, T. Hasama, H. Ishikawa, S. Fujisaki, S. Tanaka, and S. Tsuji, Appl. Phys. Express 4, $082102(2011)$.

16) H. Amano, N. Sawaki, I. Akasaki, and Y. Toyoda, Appl. Phys. Lett. 48, 353 (1986).

17) H. Amano, M. Kito, K. Hiramatsu, and I. Akasaki, Jpn. J. Appl. Phys. 28, L2112 (1989).

18) S. Nakamura, Jpn. J. Appl. Phys. 30, L1705 (1991).

19) S. Nakamura and T. Mukai, Jpn. J. Appl. Phys. 31, L1457 (1992).

20) I. Akasaki and H. Amano, Jpn. J. Appl. Phys. 45, 9001 (2006).

21) S. Nakamura, M. Senoh, N. Iwasa, S. Nagahama, T. Yamada, and T. Mukai, Jpn. J. Appl. Phys. 34, L1332 (1995)

22) S. Nakamura, M. Senoh, S. Nagahama, N. Iwasa, T. Yamada, T. Matsushita, H. Kiyoku, and Y. Sugimoto, Jpn. J. Appl. Phys. 35, L74 (1996).

23) S. Nakamura, M. Senoh, S. Nagahama, N. Iwasa, T. Yamada, T. Matsushita, H. Kiyoku, Y. Sugimoto, T. Kozaki, H. Umemoto, M. Sano, and K. Chocho, Jpn. J. Appl. Phys. 37, L309 (1998).

24) S. Nakamura, Semicond. Sci. Technol. 14, R27 (1999).

25) S. Nakamura and G. Fasol, The Blue Laser Diode: GaN Based Light Emitters and Lasers (Springer, Berlin, 1997).

26) Y. Narukawa, I. Niki, K. Izuno, M. Yamada, Y. Murazaki, and T. Mukai, Jpn. J. Appl. Phys. 41, L371 (2002).

27) Y. Narukawa, M. Sano, M. Ichikawa, S. Minato, T. Sakamoto, T. Yamada, and T. Mukai, Jpn. J. Appl. Phys. 46, L963 (2007).

28) K. Ohta and M. Koshiba, Oyo Buturi 81, 493 (2012) [in Japanese].

29) N. Kuroda, K. Shibahara, W. S. Yoo, S. Nishino, and H. Matsunami, Extended Abstracts, 19th Conf. on 
Solid State Devices and Materials, Tokyo, 1987, p. 227.

30) K. Shibahara, N. Kuroda, S. Nishino, and H. Matsunami, Jpn. J. Appl. Phys. 26, L1815 (1987).

31) R.F. Davis, G. Kelner, M. Shur, J.W. Palmour, and J.A. Edmond, Proc. IEEE 79, 677 (1991).

32) P.A. Ivanov, V.E. Chelnokov, Semicond. Sci. Technol. 7, 863 (1992).

33) M. Bhatnagar and B.J. Baliga, IEEE Trans. Electron Devices 40, 645 (1993).

34) H. Matsunami and T. Kimoto, Mat. Sci. \& Eng. R 20, 125 (1997).

35) H. Takasu, Oyo Buturi 82, 227 (2013) [in Japanese].

36) U.K. Mishra, Proc. IEEE 90, 1022 (2002).

37) S.L. Selvaraj, T. Suzue, and T. Egawa, IEEE Electron Device Lett. 30, 587 (2009).

38) N. Ikeda, Y. Niiyama, H. Kambayashi, Y. Sato, T. Nomura, S. Kato, and S. Yoshida, Proc. IEEE 98, 1151 (2010)

39) H. Kambayashi, Y. Satoh, S. Ootomo, T. Kokawa, T. Nomura, S. Kato, T. P. Chow, Solid-State Electron. 54, 660 (2010).

40) Y. Uemoto, M. Hikita, H. Ueno, H. Matsuo, H. Ishida, M. Yanagihara, T. Ueda, T. Tanaka, and D. Ueda, IEEE Trans. Electron Devices 54, 3393 (2007).

41) S. Shikata, Oyo Buturi 82, 299 (2013) [in Japanese].

42) H. Shiomi, Y. Nishibayashi, and N. Fujimori, Jpn. J. Appl. Phys. 28, L2153 (1989).

43) M.W. Geis, Proc. IEEE 79, 669 (1991).

44) H. Kawarada, M. Aoki, and M. Ito, Appl. Phys. Lett. 65, 1563 (1994).

45) Ü. Özgür, D. Hofstetter, and H. Morkoç, Proc. IEEE 98, 1255 (2010).

46) K. Nakahara and M. Kawasaki, Oyo Buturi 80,314 (2011) [in Japanese].

47) M. A. L. Johnson, S. Fujita, W. H. Rowland, Jr., W. C. Hughes, J. W. Cook, Jr., and J. F. Schetzina, J. Electron. Mater. 25, 855 (1996)

48) Y. Segawa, A. Ohtomo, M. Kawasaki, H. Koinuma, Z. K. Tang, P. Yu, and G. K. L. Wong, Phys. Stat. Sol. B 202, 669 (1997).

49) S. Niki, H. Tanpo, and H. Shibata, Oyo Buturi 77, 500 (2008) [in Japanese]. 
50) T. Oshima, T. Okuno, N. Arai, N. Suzuki, H. Hino, and S. Fujita, Jpn. J. Appl. Phys. 48, 011605 (2009).

51) S. Fujita, T. Oshima, and K. Kaneko, Oyo Buturi 78, 1150 (2009) [in Japanese].

52) K. Sasaki, A. Kuramata, T. Masui, E. G. Villora, K. Shimamura, and S. Yamakoshi, Appl. Phys. Express 5, 035502 (2012).

53) Courtesy of Professor Yoichi Kawakami, Kyoto University.

54) Y. Narukawa, Y. Kawakami, M. Funato, S. Fujita, Sg. Fujita, and S. Nakamura, Appl. Phys. Lett. 70, 981 (1997).

55) T. Mukai, M. Yamada, and S. Nakamura, Jpn. J. Appl. Phys. 38, 3976 (1999).

56) M. R. Krames, O. B. Shchekin, R. Mueller-Mach, G. O. Mueller, L. Zhou, G. Harbers, and M. G. Craford, J. Display Technol. 3, 160 (2007).

57) Y. C. Shen, G. O. Mueller, S. Watanabe, N. F. Gardner, A. Munkholm, and M. R. Krames, Appl. Phys. Lett. 91, 141101 (2007).

58) K. T. Delaney, P. Rinke, and C. G. Van de Walle, Appl. Phys. Lett. 94, 191109 (2009).

59) J. Piprek, Phys. Stat. Sol. A 207, 2217 (2010).

60) Y. Kawakami, JSPS 162nd Committee, 6th Wide-Bandgap Semiconductor Workshop Material (October 25, 2012) [in Japanese].

61) H. Amano, JSPS 162nd Committee, 6th Wide-Bandgap Semiconductor Workshop Material (October 25, 2012) [in Japanese].

62) Y. Yoshizumi, T. Yoshida, T. Kyono, M. Ueno, and T. Nakamura, SEI Tech. Rev. 179, 48 (2011) [in Japanese].

63) A. Kaneta, M. Funato, and Y. Kawakami, Phys. Rev. B 78, 125317 (2008).

64) A. Kaneta, R. Fujimoto, T. Hashimoto, K. Nishimura, M. Funato, and Y. Kawakami, Rev. Sci. Instrum. 83, 083709 (2012).

65) A. Kaneta, T, Hashimoto, K. Nishimura, M. Funato, and Y. Kawakami, Appl. Phys. Exp. 3, 102102 (2010).

66) H. Hirayama, S. Fujikawa, Y. Tsukada, and N. Kamata, Oyo Buturi, 80, 319 (2011) [in Japanese].

67) H. Hirayama, N. Noguchi, T. Yatabe, and N. Kamata, Appl. Phys. Express 1, 051101 (2008). 
68) R. G. Banal, M. Funato, and Y. Kawakami, Phys. Stat. Sol. C 7-8, 2111 (2010).

69) Y. Taniyasu, M. Kasu, and T. Makimoto, Nature 441, 325 (2006).

70) H. Hirayama, Y. Tsukada, T. Maeda, and N. Kamata, Appl. Phys. Express 3, 021002 (2010).

71) H. Hirayama, S. Fujikawa, N. Noguchi, J. Norimatsu, T. Takano, K. Tsubaki, and N. Kamata, Phys. Stat. Sol. A 206, 1176 (2009).

72) Y. Kumagai, Y. Kubota, T. Nagashima, T. Kinoshita, R. Dalmau, R. Schlesser, B. Moody, J. Xie, H. Murakami, A. Koukitu, and Z. Sitar, Appl. Phys. Express 5, 055504 (2012).

73) T. Nagashima, A. Hakomori, T. Shimoda, K. Hironaka, Y. Kubota, T. Kinoshita, R. Yamamoto, K. Takada, Y. Kumagai, A. Koukitu, and H. Yanagi, J. Cryst. Growth 350, 75 (2012).

74) T. Nomura, K. Okumura, H. Miyake, K. Hiramatsu, O. Eryu, and Y. Yamada, J. Cryst. Growth 350, 69 (2012)

75) Z. Lochner, X.-H. Li, T.-T. Kao, M. M. Satter, H. J. Kim, S.-C. Shen, P. D. Yoder, J.-H. Ryou, R.D. Dupuis, K. Sun, Y. Wei, T. Li, A. Fischer, and F. A. Ponce, Phys. Stat. Sol. A 1-3 (2013).

76) T. Oto, R. G. Banal1, K. Kataoka, M. Funato, and Y. Kawakami, Nature Photonics 4, 767 (2010).

77) NGK Insulators, Ltd., Press Release (April 25 and October 30, 2012).

78) Koninklijke Philips N.V., Press Reease (April 11, 2013).

79) T. Nakamura, 13th Nitride Semiconductor Application Workshop, Nagoya, 2011 (http://www.astf.or.jp/cluster/event/semicon/20120709/1-2.pdf) [in Japanese].

80) Kyoto University, Osaka University, Tokyo Electron Ltd., and Rohm Co., Ltd., Press Release (December 3 , 2012); Int. Electron Devices Meeting (2012).

81) Rohm Co., Ltd., Press Release (June 14, 2012).

82) T. Kimoto, 13th Nitride Semiconductor Application Workshop, Nagoya, 2011 (http://www.astf.or.jp/cluster/event/semicon/20120709/1-1.pdf) [in Japanese].

83) H. Niwa, J. Suda, and T. Kimoto, Appl. Phys. Express 5, 064001 (2012).

84) Kyoto University, Press Release (May 17, 2011).

85) http:/www.fairchildsemi.com/Assets/zSystem/documents/collateral/productOverview/silicon-carbide-tech 
nology.pdf

86) Mitsubishi Electric Corporation, Press Release (February 16, 2011).

87) Mitsubishi Electric Corporation, Press Release (September 27, 2012).

88) Mitsubishi Electric Corporation, Press Release (May 9, 2013).

89) Rohm Co., Ltd., Press Release (December 13, 2012).

90) T. Kimoto, JSPS 162nd Committee, 6th Wide-Bandgap Semiconductor Workshop Material(October 25, 2012) [in Japanese].

91) S. Ha, P. Mieszkowskia, M. Skowronskia, and L. B. Rowland, J. Cryst. Growth 244, 257

92) T. Ohno, H. Yamaguchi, S. Kuroda, K. Kojima, T. Suzuki, and K. Arai, J. Cryst. Growth 271, 1 (2004).

93) M. Skowronskia and H. Ha, J. Appl. Phys. 99, 011101 (2006).

94) J. J. Sumakeris, P. Bergman, M. K. Das, C. Hallin, B. A. Hull, E. Janzén, H. Lendenmann, M. J. O' Loughlin, M. J. Paisley, S. Ha, M. Skowronski, J. W. Palmour, and C. H. Carter Jr., Mater. Sci. Forum 527-529, 141 (2006).

95) H. Song and T. S. Sudarshan, Cryst. Growth Des. 12, 1703 (2012).

96) K. Nakayama, Y. Sugawara, H. Tsuchida, C. Kimura and H. Aoki, Jpn. J. Appl. Phys. 50 04DF04 (2011).

97) N. Ohtani, Oyo Buturi 82, 846 (2013) [in Japanese].

98) R. Schoerner, P. Friedrichs, D. Peters, and D. Stephani, IEEE Electron Devices Lett. 20, 241 (1999).

99) K. Ueno, R. Asai, and T. Tsuji, Mater. Sci. Eng., B 61-62, 472 (1999).

100) H. Yano, T. Kimoto, H. Matsunami, M. Bassler, and G. Pensl, Mater. Sci. Forum 338-342, 1109 (2000).

101) E. Bano, C. Banc, T. Ouisse, and S. Scharnholz, Solid-State Electron. 44, 63 (2000).

102) N. S. Saks, S. S. Mani, and A. K. Agarwal, Appl. Phys. Lett. 76, 2250 (2000).

103) H. Yano, T. Hirao, T. Kimoto, H. Matsunami, K. Asano, and Y. Sugawara, IEEE Electron Devices Lett. 20, 611 (1999).

104) H. Yano, T. Hirao, T. Kimoto, and H. Matsunami, Appl. Phys. Lett. 78, 374 (2001).

105) K. Fukuda, M. Kato, K. Kojima, and J. Senzaki, Appl. Phys. Lett. 84, 2088 (2004).

106) L. A. Liupkin, M. K. Das, and J. W. Palmour, Mat. Sci. Forum 389-393, 985 (2002). 
107) T. Kimoto, Y. Kanzaki, M. Noborio, H. Kawano, and H. Matsunami, Jpn. J. Appl. Phys. 44, 1213 (2005).

108) J. Senzaki, A. Shimozato, K. Kajima, K. Aryoshi, T. Kojima, S. Harada, Y. Tanaka, H. Himi, and H. Okumura, Mater. Sci. Forum, 740-742, 621 (2013).

109) T. Okayama, S. D. Arthur, J. L. Garrett, and M. V. Rao, Solid-State Electron. 52, 164 (2008).

110) X. Shen, E. X. Zhang, C. X. Zhang, D. M. Fleetwood, R. D. Schrimpf, S. Dhar, S.-H. Ryu, and S. T. Pantelides, Appl. Phys. Lett. 98, 063507 (2011).

111) H. Yano, Y. Oshiro, D. Okamoto, T. Hatayama, and T. Fuyuki, Mater. Sci. Forum 679-680, 603 (2011).

112) A. Lelis, R. Green, and D. Habersat, ECS Trans. 41, 203 (2011).

113) A. Chanthaphan, T. Hosoi, Y. Nakano, T. Nakamura, T. Shimura, and H. Watanabe, Appl. Phys. Lett. 102, 093510 (2013).

114) S. DasGupta, R. Brock, R. Kaplar, M. Marinella, M. Smith, and S. Atcitty, Appl. Phys. Lett. 99, 023503 (2011).

115) T. Umeda, M. Okamoto, R. Kosugi, S. Harada, R. Arai, Y. Sato, T. Makino, and T. Ohshima, ECS Trans. 58, 55 (2013).

116) A. Lelis, D. Habersat, R. Green, and E. Mooroa, ECS Trans. 58, 87 (2013).

117) M. Okamoto, Y. Makifuchi, M. Iijima, Y. Sakai, N. Iwamuro, H. Kimura, K. Fukuda, and H. Okumura, Appl. Phys. Express 5, 041302 (2012).

118) Y. K. Sharma, A. C. Ahyi, T. Isaacs-Smith, A. Modic, M. Park, Y. Xu, E. L. Garfunkel, S. Dhar, L. C. Feldman, and J. R. Williams, IEEE Electron Device Lett. 34, 175 (2013).

119) T. Umeda, R. Kosugi, Y. Sakuma, Y. Satoh, H. Okamoto, S. Harada, and T. Ohshima, ECS Trans. 50, 305 (2012).

120) T. Hayashi, Dr. Thesis, Faculty of Engineering, Kyoto University, Kyoto (2013), p. 17 [in Japanese].

121) T. Kimoto, N. Miyamoto, and H. Matsunami, Mat. Sci. Eng. B 61-62, 349 (1999).

122) T. Tawara, H. Tsuchida, S. Izumi, I. Kamata, and K. Izumi, Mater. Sci. Forum 457-460, 565 (2004).

123) P. B. Klein, B. V. Shanabrook, S. W. Huh, A. Y. Polyakov, M. Skowronski, J. J. Sumakeis, and M. J. O'Loughlin, Appl. Phys. Lett. 88, 052110 (2006). 
124) T. Kimoto, K. Danno, and J. Suda, Phys. Stat. Sol. B 245, 1327 (2008).

125) K. Danno, K. Hashimoto, H. Saitoh, T. Kimoto, and H. Matsunami, Jpn. J. Appl. Phys. 43, L969 (2004).

126) L. Strasta and H. Tsuchida, Appl. Phys. Lett. 90, 062116 (2007).

127) T. Hiyoshi and T. Kimoto, Appl. Phys. Express 2, 041101 (2009).

128) T. Miyazawa, M. Ito, and H. Tsuchida, Appl. Phys. Lett. 97, 202106 (2010).

129) S. Ichikawa, K. Kawahara, J. Suda, and T. Kimoto, Appl. Phys. Express 5, 101351 (2012).

130) T. Hayashi, K. Asano, J. Suda, and T. Kimoto, J. Appl. Phys. 109, 114502 (2011).

131) T. Hayashi, K. Asano, J. Suda, and T. Kimoto, J. Appl. Phys. 112, 064503 (2012).

132) M. Maeda, Manufacturing \& Technology 65, 75 (2013) [in Japanese].

133) K. Inoue, S. Sano, Y. Tateno, F. Yamaki, K. Ebihara, N. Ui, A. Kawano, and H. Deguchi, SEI Tech. Rev. 177, 97 (2010) [in Japanese].

134) R. J. Trew, Proc. IEEE 90, 1032 (2002)

135) R. Pengelly, S. M. Wood, J. W. Milligan, S. T. Sheppard, and W. L. Pribble, IEEE Trans. Microwave Theory and Techniques 60, 1764 (2012).

136) N. Maeda, 12th Nitride Semiconductor Application Workshop, Nagoya, 2011 (http://www.astf.or.jp/cluster/event/semicon/20111110/06.pdf) [in Japanese].

137) T. Yoshikawa, M. Kanamura, T. Taki, M. Nishimori, S. Ozaki, Y. Minoura, N. Okamoto, K. Joshin, and K. Watanabe, JSPS 162nd Committee of Wide-Bandgap Semiconductor Optical and Electron Devices, 80th Workshop Materials, 2012, p. 29 [in Japanese].

138) T. Ueda, KEC Information 224, 35 (2013) [in Japanese].

139) Sharp Corporation, Press Release (March 14, 2013).

140) Yasukawa Electric Corporation, Press Release (October 31, 2012).

141) Hitachi Cable Ltd., Press Release (September 3, 2012).

142) G. Simin, A. Koudymov, A. Tarakji, X. Hu, J. Yang, M.A. Khan, M.S. Shur, and R. Gaska, Appl. Phys. Lett. 79, 2651 (2001).

143) R. Vetury, N. Q. Zhang, S. Keller, and U. K. Mishra, IEEE Trans. Electron Devices 48, 560 (2001). 
144) S. Binari, K. Ikossi, J.A. Roussos, W. Kruppa, D. Park, H. B. Dietrich, D. D. Koleske, A. E.Wickenden, and R. L. Henry, IEEE Trans. Electron Devices 48, 465 (2001).

145) Y. Ohno, S. Kishimoto, K. Maezawa, and T. Mizutani, IEICE Tech. Rep. ED2001-187, MW2001-142, ICD2001-184 (2002) [in Japanese].

146) T. Mizutani, Y. Ohno, M. Akita, S. Kishimoto, and K. Maezawa, IEEE Trans. Electron Devices 50, 2015 (2003).

147) N. Ikeda, J. Li, K. Kato, S. Kaya, T. Kazama, T. Kokawa, Y. Sato, M. Iwami, T. Nomura, M. Masuda, and S. Kato, Furukawa Elect. Rev. 122, 20 (2008) [in Japanese].

148) W. Saito, T. Nitta, Y. Kakuuchi, Y. Saito, K. Tsuda, and I. Omura, IEEE Electron Device Lett. 28, 676 (2007).

149) S. Iwakami, O. Machida, M. Yanagihara, T. Ehara, N. Kaneko, H. Goto, and A. Iwabuchi, Jpn. J. Appl. Phys. 46, L587 (2007).

150) Y. Ohno, JSPS 162nd Committee of Wide-Bandgap Semiconductor Optical and Electron Devices, 81st Workshop Material, 2012, p. 17 [in Japanese].

151) J. Wuerfl, E. Bahat-Treidel, F. Brunner, E. Cho, O. Hilt, P. Ivo, A. Knauer, P. Kurpas, R. Lossy,M. Schulz, S. Singwald,M.Weyers, and R. Zhytnytska, Microelectron. Rel. 51, 1710 (2011).

152) M. Araghchini, J. Chen, V.D. Nguyen, D.V. Harburg, D. Jin, J. Kim, M.S. Kim, S. Lim, B. Lu, D. Piedra, J. Qiu, J. Ranson, M. Sun, X. Yu, H. Yun, M.G. Allen, J.A. del Alamo, G. DesGroseilliers, F. Herrault, J.H. Lang, C.G. Levey, C.B. Murray, D. Otten, T. Palacios, D.J. Perreault, and C.R. Sullivan, IEEE Trans. Power Electronics 28, 4182 (2013).

153) Courtesy of Professor Tamotsu Hashizume, Hokkaido University.

154) H. Amano, Jpn. J. Appl. Phys. 52, 050001 (2013).

155) A. Usui, T. Ichihashi, K. Kobayashi, H. Sunakawa, Y. Oshima, T. Eri, and M. Shibata, Phys. Stat. Sol. A 194, $572(2002)$.

156) K. Fujito, S. Kubo, H. Nagaoka, T. Mochizuki, H. Namita, and S. Nagao, J. Cryst. Growth 311, 3011 (2009). 
157) T. Yoshida, Y. Oshima, K. Watanabe, T. Tsuchiya, and T. Mishima, Phys. Stat. Sol. C 8, 2110 (2011).

158) A. Usui, T. Matsueda, H. Goto, H. Sunakawa, Y. Fujiyama, Y. Ishihara, A. Okada, S. Shoji, A. A. Yamaguchi, H. Nishihara, H. Shinohara, H. Goto, and J. Mizuno, Jpn. J. Appl. Phys. 52, 08 JB02 (2013).

159) S. Porowski, J. Cryst. Growth 166, 583 (1996).

160) S. Porowski and I. Grzegory, J. Cryst. Growth 178, 174 (1997).

161) A. Yoshikawa, E. Ohshima, T. Fukuda, H. tsuji, and K. Oshima, J. Cryst. Growth 260, 67 (2004).

162) T. Hashimoto, F. Wu, J. S. Speck, and S. Nakamura, Nat. Mater. 6, 568 (2007).

163) R. Dwillinski, R. Doradzinski, J. Garczynski, L. Sierzputowski, R. Kucharski, M. Zajac, M. Rudzinski, R. Kudrawiec, W. Strupinski, an J. Misiewicz, Phys. Stat. Sol. A 208, 1489 (2011).

164) H. Yamada, M. Shimada, T. Sekiguchi, and F. J. DiSalvo, Chem. Mater. 9, 413 (1997).

165) Y. Mori, Y. Kitaoka, M. Imade, N. Miyoshi, Y. Yoshimura, and T. Sasaki, Phys. Stat. Sol. A 207, 1269 (2010).

166) Y. Mori, Y. Kitaoka, M. Imade, N. Miyoshi, Y. Yoshimura, and T. Sasaki, Phys. Stat. Sol. C 8, 1445 (2011).

167) Y. Mori, M. Imade, K. Murakami, H. Takazawa, H. Imabayashi, Y. Todoroki, K. Kitamoto, M. Maruyama, M. Yoshimura, Y. Kitamoto, and T. Sasaki, J. Cryst. Growth 350, 72 (2012).

168) T. Funaki, M. Hirano, H. Umezawa, and S. Shikata, IEICE Electron. Express 9, 1835 (2012).

169) T. Iwasaki, Y. Hoshino, K. Tsuzuki, H. Kato, T. Makino, M. Ogura, D. Takeuchi, T. Matsumoto, H. Okushi, S. Yamasaki, and M. Hatano, Appl. Phys. Express 5, 091301 (2012).

170) H. Kato, H. Umezawa, N. Tokuda, D. Takeuchi, H. Okushi, and S. Yamasaki, Appl. Phys. Lett. 93 (2008) 202103.

171) H. Kato, T. Makino, M. Ogura, N. Tokuda, H. Okushi, and S. Yamasaki, Appl. Phys. Express 2, 055502 (2009).

172) Y. Hoshino, H. Kato, T. Makino, M. Ogura, T. Iwasaki, M. Hatano, and S. Yamasaki, Phys. Stat. Sol. A 209, 1761 (2012).

173) M. Kasu and M. Kubovic, Jpn. J. Appl. Phys. 49, 110209 (2010).

174) E. A. Ekimov, V. A. Sidorov, E. D. Bauer, N. N. Mel'nik, N. J. Curro, J. D. Thompson, and S. M. Stisho, 
Nature 428, 542 (2004).

175) N. Ueda, H. Hosono, R. Waseda, and H. Kawazoe, Appl. Phys. Lett. 70, 3561 (1997)

176) E. G. Villora, K. Shimamura, Y. Yoshikawa, K. Aoki, and N. Ichinose, J. Cryst. Growth 270, 420 (2004).

177) K. Shimamura, E. G. Villora, K. Muramatsu, K. Aoki, M. Nakamura, S. Takekawa, N. Ichinose, and K. Kitamura, J. Jpn. Assoc. Cryst. Growth 33, 147 (2006) [in Japanese].

178) N. Suzuki, S. Ohira, M. Tanaka, T. Sugawara, K. Nakajima, and T. Shishido, Phys. Stat. Sol. C 4, 2310 (2007).

179) H. Aida, K. Nishiguchi, H. Takeda, N. Aota, K. Sunakawa, and Y. Yaguchi, Jpn. J. Appl. Phys. 47, 8506 (2008).

180) M. Higashiwaki, K. Sasaki, T. Kamimura, M. H. Wong, D. Krishnamurthy, A. Kuramata, T. Masui, and S. Yamakoshi, Appl. Phys. Lett. 103, 123511 (2013).

181) T. Oshima, T. Okuno, N. Arai, Y. Kobayashi, and S. Fujita, Jpn. J. Appl. Phys. 48, 070202 (2009).

182) K. Sasaki, M. Higashiwaki, A. Kuramata, T. Masui, and S. Yamakoshi, Appl. Phys. Express 6, 086502 (2013).

183) T. Oshima, T. Okuno, N. Arai, N. Suzuki, S. Ohira, and S. Fujita, Appl. Phys. Express 1, 011202 (2008).

184) T. Oshima, K. Kaminaga, A. Mukai, K. Sasaki, T. Masui, A. Kuramata, S. Yamakoshi, S. Fujita, and A. Ohtomo, Jpn. J. Appl. Phys. 52, 051101 (2013).

185) N. Ichinose and K. Shimamura, Japan Patent 342857 (2004).

186) K. Shimamura, E. G. Villora, K. Domen, K. Yui, K. Aoki, and N. Ichinose, Jpn. J. Appl. Phys. 44, L7 (2005).

187) S. Ohira, M. Yoshioka, T. Sugawara, K. Nakajima, and T. Shishido, Thin Solid Films 496, 53 (2006).

188) S. Ohira, N. Suzuki, H. Minami, K. Takahashi, T. Araki, and Y. Nanishi, Phys. Stat. Sol. C 4, 2306 (2007).

189) S. Akasaka, A. Tsukazaki, K. Nakahara, A. Ohtomo, and M. Kawasaki, Jpn. J. Appl. Phys. 50, 080215 (2011).

190) Y. Kozuka, J. Falson, Y. Segawa, T. Makino, A. Tsukazaki, and M. Kawasaki, J. Appl. Phys. 112, 043515 (2012). 
191) T. Makino, Y. Segawa, A. Tsukazaki, H. Saito, S. Takeyama, S. Akasaka, K. Nakahara, M. Kawasaki, Phys. Rev. B 87, 085312 (2013).

192) Y. Kozuka, S. Teraoka, J. Falson, A. Oiwa, A. Tsukazaki, S. Tarucha, and M. Kawasaki, Phys. Rev. B 87, 205411 (2013).

193) M. E. White, M. Y. Tsai, F. Wu, and J. S. Speck, J. Vac. Sci. Technol. A 26, 1300 (2008).

194) T. Oshima, T. Okuno, and S. Fujita, Jpn. J. Appl. Phys. 48, 120207 (2009).

195) T. Okuno, T. Oshima, S.-D. Lee, and S. Fujita, Phys. Stat. Sol. C 8, 540 (2011).

196) K. Uchida, K. Yoshida, D. Zhang, A. Koizumi, and S. Nozaki, AIP Adv. 2, 042154 (2012).

197) J. Li, Z. Mei, D. Ye, H. Liang, Y. Liu, X. Du, J. Cryst. Growth 353, 63 (2012).

198) D. Shinohara and S. Fujita, Jpn. J. Appl. Phys. 47, 7311 (2008).

199) N. Suzuki, K. Kaneko, and S. Fujita, J. Cryst. Growth 364, 30 (2013).

200) K. Kaneko, T. Nomura, I. Kakeya, and S. Fujita, Appl. Phys. Express 2, 075501 (2009).

201) K. Kaneko, I. Kakeya, S. Komori, and S. Fujita, J. Appl. Phys. 113, 233901 (2013).

202) Y. Takeda and A. Sasaki, Jpn. J. Appl. Phys. Suppl. 20-1, 189 (1981).

203) K. Shibahara, S. Nishino, and H. Matsunami, J. Jpn. Assoc. Cryst. Growth 13, 226 (1987) [in Japanese].

204) H. Matsunami, J. Jpn. Assoc. Cryst. Growth 33, 12 (2006) [in Japanese].

205) H. Mitsuhashi, I. Mitsuishi, and H. Kukimoto: Jpn. J. Appl. Phys. 24, L864 (1985).

206) S. Fujita, K. Terada, T. Sakamoto, and Sg. Fujita: J. Cryst. Growth. 94, 102 (1989).

207) K. Katayama, H. Yao, F. Nakanishi, H. Doi, A. Saegusa, N. Saegusa, N. Okuda, T. Yamada, H. Matsubara, M. Irikura, T. Matsuoka, T. Takebe, S. Nishine, and T. Shirakawa, Appl. Phys. Lett. 73, 102 (1998).

208) T. P. Chow, ECS Transactions 60, 1039 (2014).

209) J. Millán, IEEE Trans. Power Electronics 29, 2155 (2014).

210) T. Matsuoka, A. Yamamoto, K. Tadatomo, T. Suemitsu, and Y. Ishitani, Eds., in "Selected Topics in Applied Physics", Jpn. J. Appl. Phys. 53, 100200 (2014).

211) Odakyu Electric Railway Co., Ltd., Press Release (April 30, 2014).

212) Mitsubishi Electric Corporation, Press Release (May 15, 2014). 
213) R. H. Kikuchi and K. Kita, Appl. Phys. Lett. 105, 032106 (2014);

214) S. Sato, Y. Hiroi, K. Yamabe, M. Kitabatake, T. Endoh, and M. Niwa, Jpn. J. Appl. Phys. 53, 08LA01 (2014).

215) T. Oka, Y. Ueno, T. Ina, and K. Hasegawa, Appl. Phys. Express 7, 021002 (2014).

216) J. J. Freedsman, T. Egawa, Y. Yamaoka, Y. Yano, A. Ubukata, T. Tabuchi, and K. Matsumoto, Appl. Phys. Express 7, 041003 (2014).

217) H. Umezawa, S. Shikata, and T. Funaki, Jpn. J. Appl. Phys. 53, 05FP06 (2014)

218) J.-I. Hwang, R. Hashimoto, S. Saito, and S. Nunoue, Appl. Phys. Express 7, 071003 (2014).

219) J. R. Pryde, D. C. Whalley, and W. Malalasekera, Proc. 14th InterSociety Conf. on Thermal and Thermomechanical Phenomena in Electronic Systems (ITherm 2014), Orlando, USA, p.31 (2014).

220) Y. Nanishi, Nat. Photonics 8, 884 (2014).

221) K. Sasaki, M. Higashiwaki, A. Kuramata, T. Masui, and S. Yamakoshi, J. Cryst. Growth 392, 30 (2014).

222) H. Okumura, M. Kita, K. Sasaki, A. Kuramata, M. Higashiwaki, and J. S. Speck, Appl. Phys. Express 7, 095501 (2014).

223) T. Kamimura, K. Sasaki, M. H. Wong, D. Krishnamurthy, A. Kuramata, T. Masui, S. Yamakoshi, and M. Higashiwaki, Appl. Phys. Lett. 104, 192104 (2014).

224) M. Seki, M. Takahashi, T. Ohshima, H. Yamahara, and H. Tabata, Jpn. J. Appl. Phys. 53, $05 F A 07$ (2014).

225) K. Kaneko, S. Ueda, and S. Fujita, 32nd Int. Conf. Physics of Semiconductors, Austin, USA, Session: Wide Band Gap III (2014).

226) S. Fujita and K. Kaneko, J. Cryst. Growth 401, 588 (2014). 
Shizuo Fujita was born in Osaka in 1955. He graduated Kyoto University in 1978 and then completed a master's course at the Graduate School of Engineering, Kyoto University, in 1980. He became a research associate, and then promoted to an associate professor and a professor at Kyoto University in 1990 and 2001, respectively. He experienced a visiting scholar at North Carolina State University, USA, from 1994 to 1995 . He has been engaged in research on wide-bandgap semiconductors, such as group II-VI compound semiconductors (e.g., ZnSe), GaN, and $\mathrm{ZnO}$, and currently is studying $\mathrm{Ga}_{2} \mathrm{O}_{3}$ and other oxide semiconductors. He is a collaborating member of the Science Council of Japan and a fellow of the Japan Society of Applied Physics. 


\section{(Figure Legends)}

Fig. 1 Relationship between energy bandgap and bond length for various compound semiconductors promising for practical applications.

Fig. 2 Emission efficiency (external quantum efficiency) of LEDs with different wavelengths. ${ }^{53)}$

Fig. 3 (Top) Observation regions of CL microscope and SNOM. (Bottom) Correlation between effect of localized excitons and defects in ultrasmall region. ${ }^{63)}$ The QWs were fabricated on $\mathrm{GaN}$ templates grown by the epitaxially lateral overgrowth (ELO) technique, and the phenomena in the seed and wing regions are compared in the lateral direction of the figures (a)-(c).

Fig. 4 Improvement of efficiency for deep-UV and UV LEDs. ${ }^{66)}$

Fig. 5 Relationships among device killer density $D\left(\mathrm{~cm}^{-2}\right)$, device area $A\left(\mathrm{~cm}^{2}\right)$, and device yield. $^{90)}$

Fig. 6 Various dislocations in $4 \mathrm{H}-\mathrm{SiC}$ substrate and their propagation to epilayer.

Fig. 7 Capacitance-voltage hysteresis reported for a 4H-SiC C-face MOS capacitor processed by wet oxidation. ${ }^{117)}$

Fig. 8 Technique for suppressing current collapse in GaN-based devices. Insertion of FP and increase in epilayer thickness. ${ }^{147)}$

Fig. 9 Examples of techniques for achieving normally-off GaN-based devices. ${ }^{153)}$

Fig. 10 Schematic structures of GaN-based MOS-HFET and GIT.

Table I Basic physical properties of various wide-bandgap semiconductor single crystals. Values for $\mathrm{Si}, \mathrm{GaAs}, 4 \mathrm{H}-\mathrm{SiC}, \mathrm{GaN}$, and diamond are after the ref.2. For $\mathrm{ZnO}$ and $\mathrm{Ga}_{2} \mathrm{O}_{3}$, the sources are given by the reference numbers.

Table II Type and density of defects in $\mathrm{SiC}$ and their effects on decrease in breakdown voltage. $^{90)}$ 
Table III

Defect densities analyzed in diamond substrates. ${ }^{41)}$ 


\begin{tabular}{|c|c|c|c|c|c|c|c|}
\hline & $\mathrm{Si}$ & GaAs & $4 \mathrm{H}-\mathrm{SiC}$ & $\mathrm{GaN}$ & $\mathrm{ZnO}$ & $\beta-\mathrm{Ga}_{2} \mathrm{O}_{3}$ & Diamond \\
\hline Bandgap (eV) & 1.12 & 1.4 & 3.2 & 3.39 & 3.4 & $4.8-4.9$ & 5.6 \\
\hline Band Structure & $\begin{array}{l}\text { Indirect } \\
\text { transition }\end{array}$ & $\begin{array}{c}\text { Direct } \\
\text { transition }\end{array}$ & $\begin{array}{l}\text { Indirect } \\
\text { transition }\end{array}$ & $\begin{array}{c}\text { Direct } \\
\text { transition }\end{array}$ & $\begin{array}{c}\text { Direct } \\
\text { transition }\end{array}$ & $\begin{array}{c}\text { Direct or } \\
\text { indirect } \\
\text { transition }\end{array}$ & \\
\hline Electron mobility $\left(\mathrm{cm}^{2} / \mathrm{Vs}\right)$ & 1,450 & 8,500 & 950 & 2,000 & 300 & $300^{7)}$ & 4,000 \\
\hline Hole mobility $\left(\mathrm{cm}^{2} / \mathrm{Vs}\right)$ & 450 & 400 & 115 & 350 & & & 3,800 \\
\hline $\begin{array}{l}\text { Breakdown electric field } \\
(\mathrm{MV} / \mathrm{cm})\end{array}$ & 0.3 & 0.4 & 3 & 5 & & $8^{7)}$ & 10 \\
\hline $\begin{array}{l}\text { Thermal conductivity } \\
\text { (W/cmK) }\end{array}$ & 1.3 & 0.54 & 5 & 1.3 & $\sim^{3)}$ & $\sim 0.2^{8)}$ & 20 \\
\hline $\begin{array}{l}\text { Electron saturation velocity } \\
(\mathrm{cm} / \mathrm{s})\end{array}$ & $1 \times 10^{7}$ & $2 \times 10^{7}$ & $2 \times 10^{7}$ & $2 \times 10^{7}$ & $3.0 \times 10^{74)}$ & & $3 \times 10^{7}$ \\
\hline Relative permitivity & 11.7 & 12.9 & 10 & 8.9 & $\sim 8^{3)}$ & 10 & 5.7 \\
\hline
\end{tabular}

Table I 


\begin{tabular}{|l||c|c|l|}
\hline \multicolumn{1}{|c||}{ Defect } & Density & $\begin{array}{c}\text { Decrease in } \\
\text { breakdown voltage }\end{array}$ & \multicolumn{1}{c|}{ Notes } \\
\hline \hline Micropipes & $0 \sim 0.1 \mathrm{~cm}^{-2}$ & $50 \sim 80 \%$ & detrimental, but eliminated \\
\hline TSDs & $500 \mathrm{~cm}^{-2}$ & $<3 \%$ & minor impacts on leakage \\
\hline TEDs & $3000 \mathrm{~cm}^{-2}$ & $<3 \%$ & minor impacts on leakage \\
\hline BPDs & $10 \mathrm{~cm}^{-2}$ & $<3 \%$ & bipolar degradation \\
\hline Stacking faults & $0.01 \sim 1 \mathrm{~cm}^{-1}$ & $20 \sim 50 \%$ & mostly detrimental \\
\hline \hline Carrot faults & $<0.1 \mathrm{~cm}^{-2}$ & $20 \sim 50 \%$ & almost eliminated \\
\hline Triangle faults & $\sim 0.1 \mathrm{~cm}^{-2}$ & $20 \sim 50 \%$ & observed on 40 off-axis \\
\hline Particles & $<0.3 \mathrm{~cm}^{-2}$ & $30 \sim 80 \%$ & technological issues \\
\hline
\end{tabular}




\begin{tabular}{|l|c|}
\hline Micropipes & None \\
\hline TEDs & $300-10000 \mathrm{~cm}^{-2}$ \\
\hline TSDs & Not available \\
\hline $\begin{array}{l}\text { Mixed-type threading } \\
\text { dislocations }\end{array}$ & $150-5000 \mathrm{~cm}^{-2}$ \\
\hline Others & Not analyzed $\sim 10000 \mathrm{~cm}^{-2}$ \\
\hline Total density of defects & $10000-100000 \mathrm{~cm}^{-2}$ \\
\hline
\end{tabular}




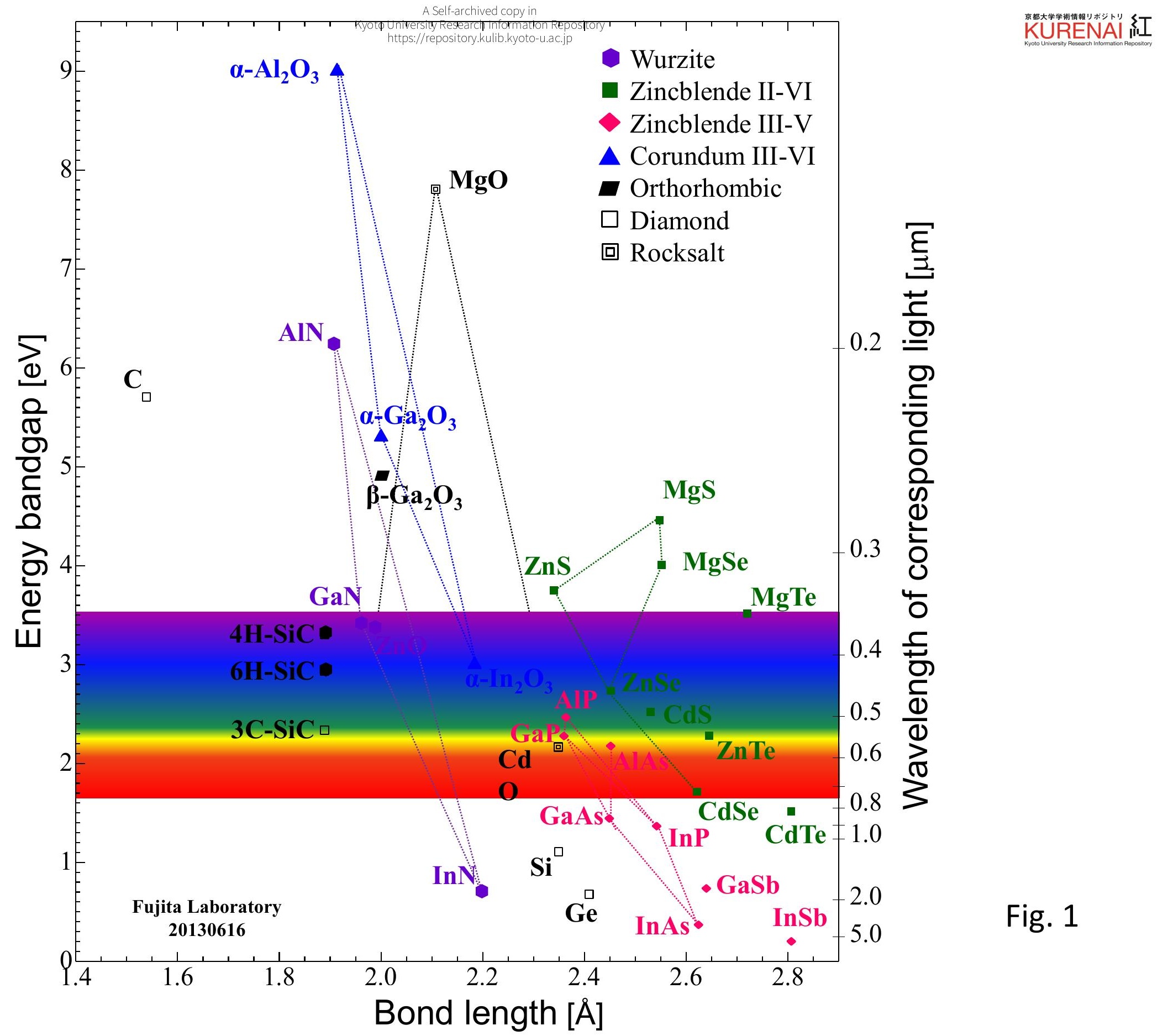




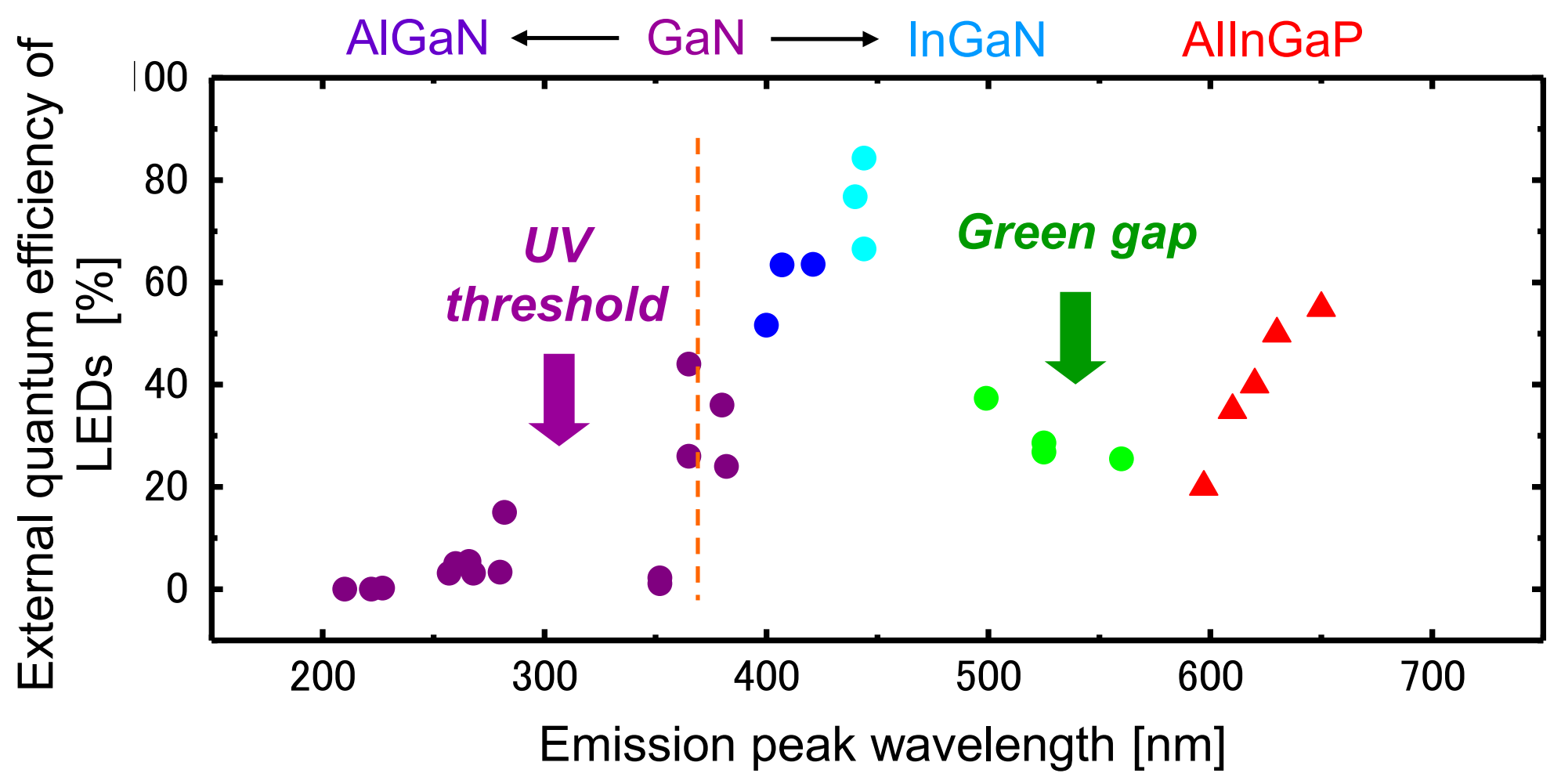

Fig. 2 

microscope (SNOM)

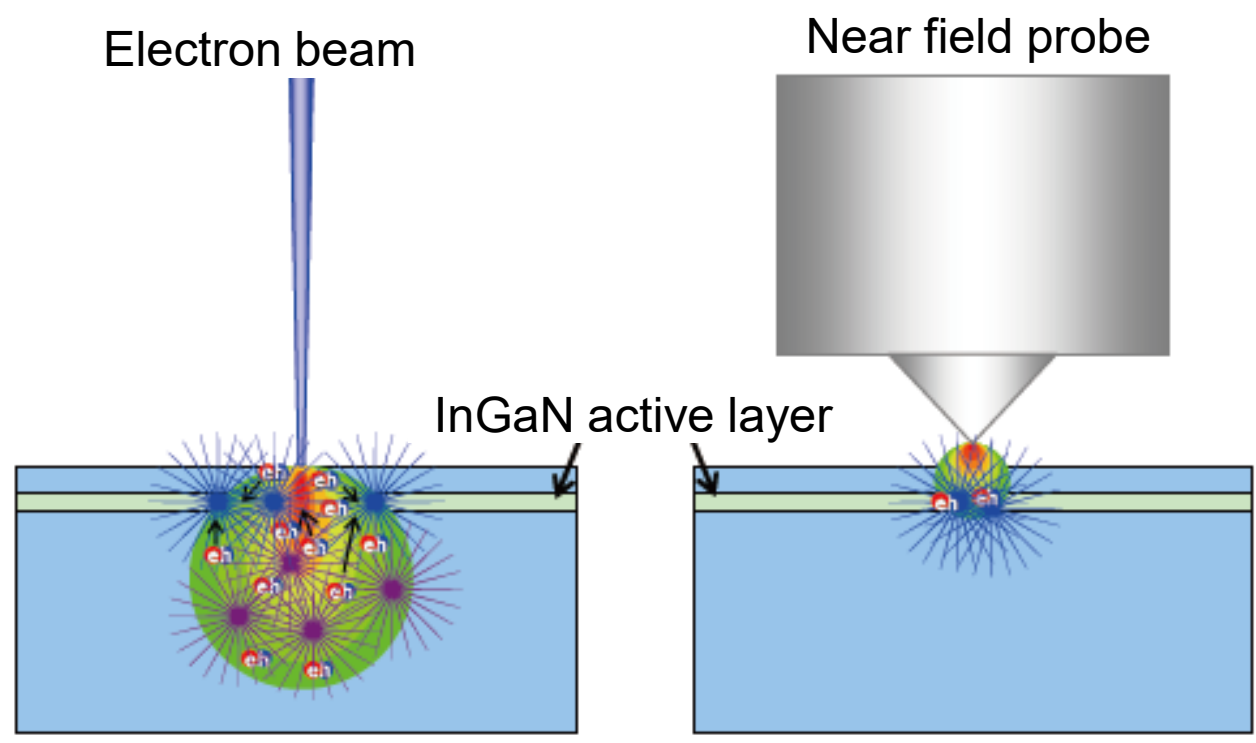

\section{Seed \\ Wing}

(a) InGaN purple emitter



Shallow

localized states

(b) InGaN blue emitter

Localization

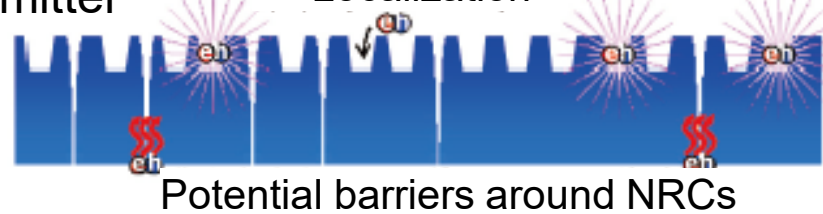

Deep

localized states

(c) InGaN green emitter

Potential bariers around NRCs

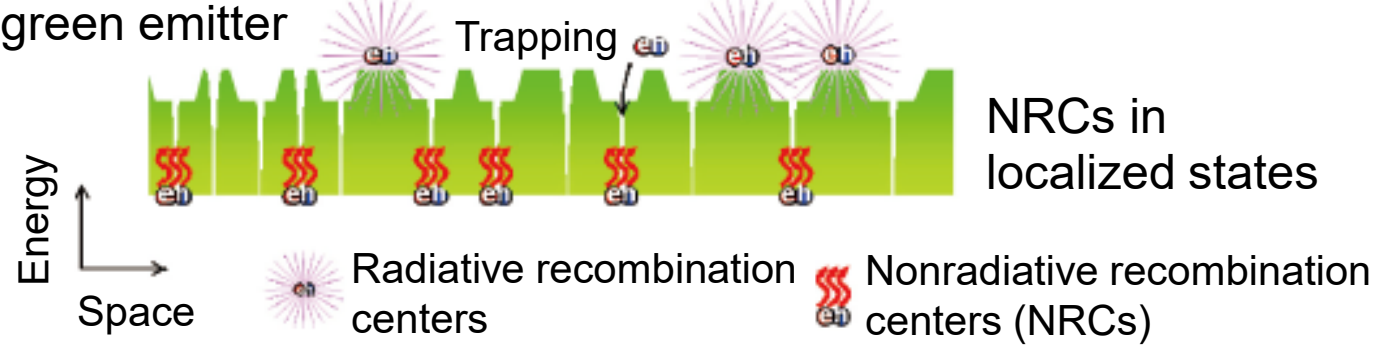

Fig. 3 


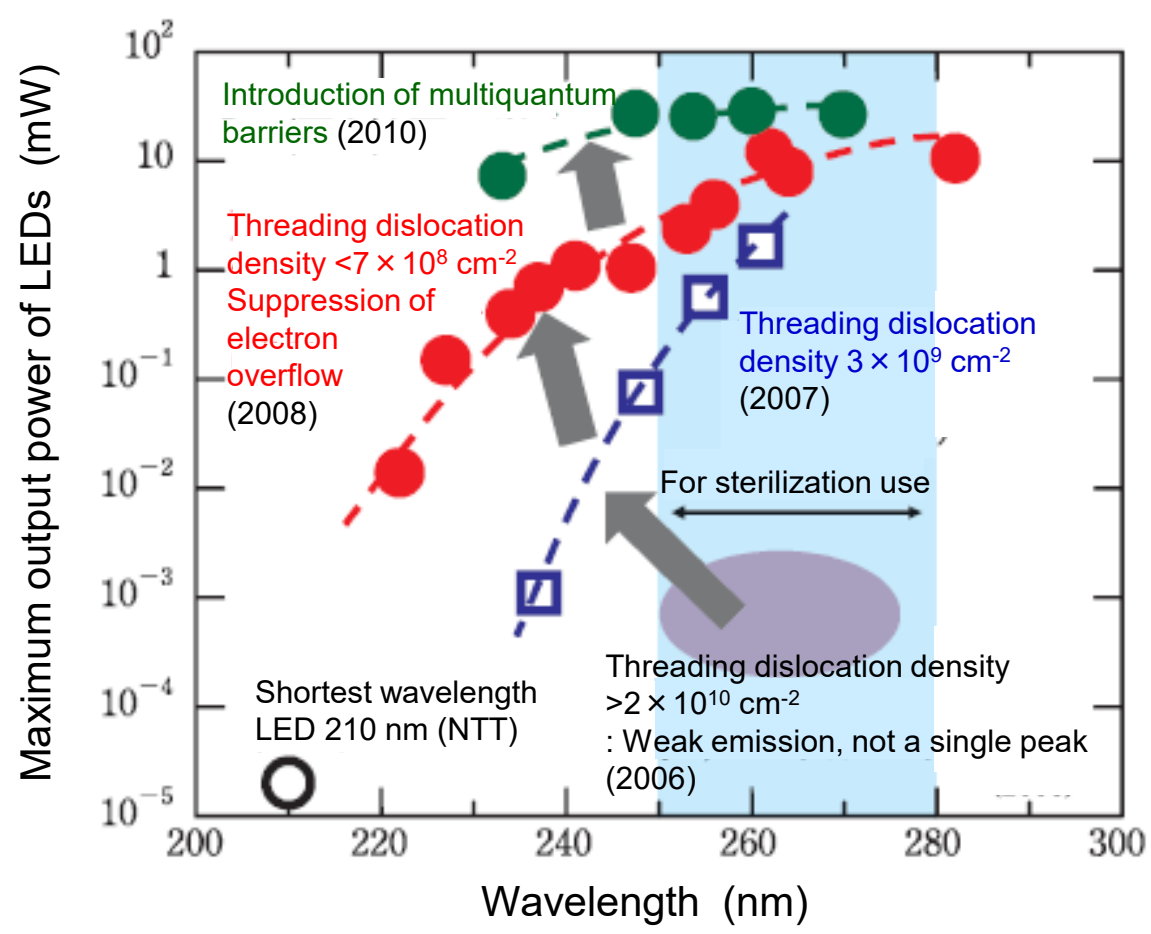

Fig. 4 


\section{Device current $[A]$}

(for fixed current density of $200 \mathrm{~A} / \mathrm{cm}^{2}$ )

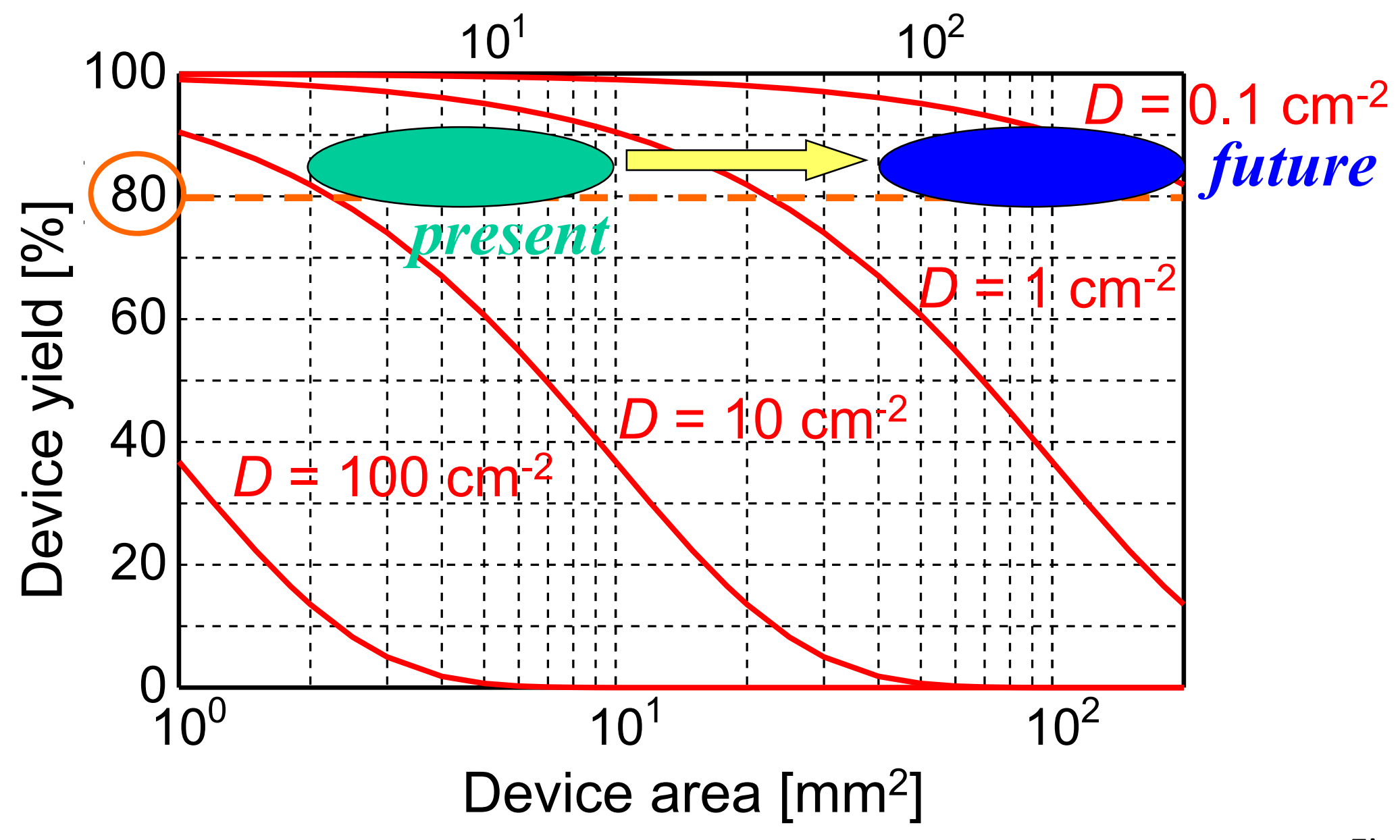

Fig. 5 

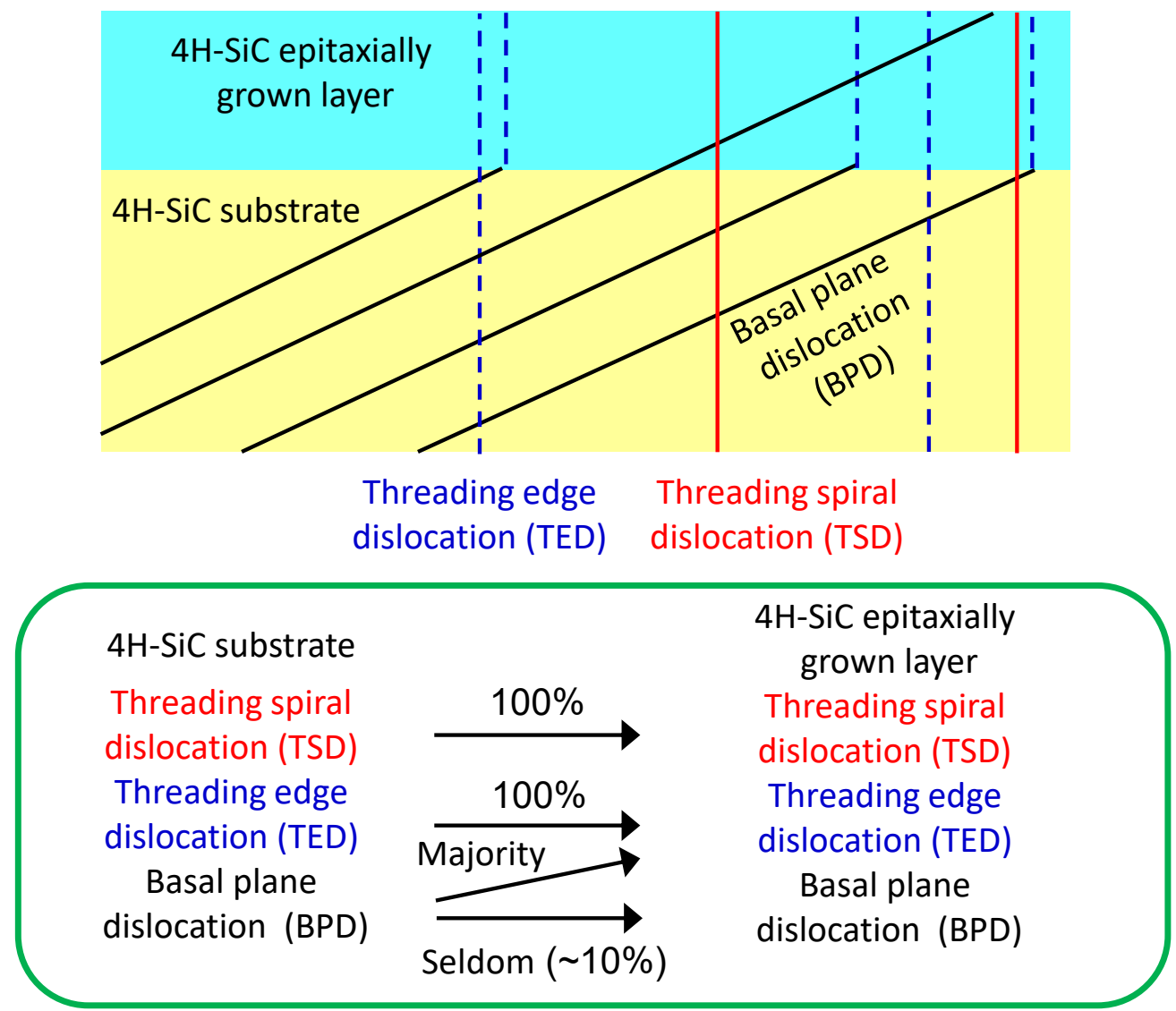

Fig. 6 


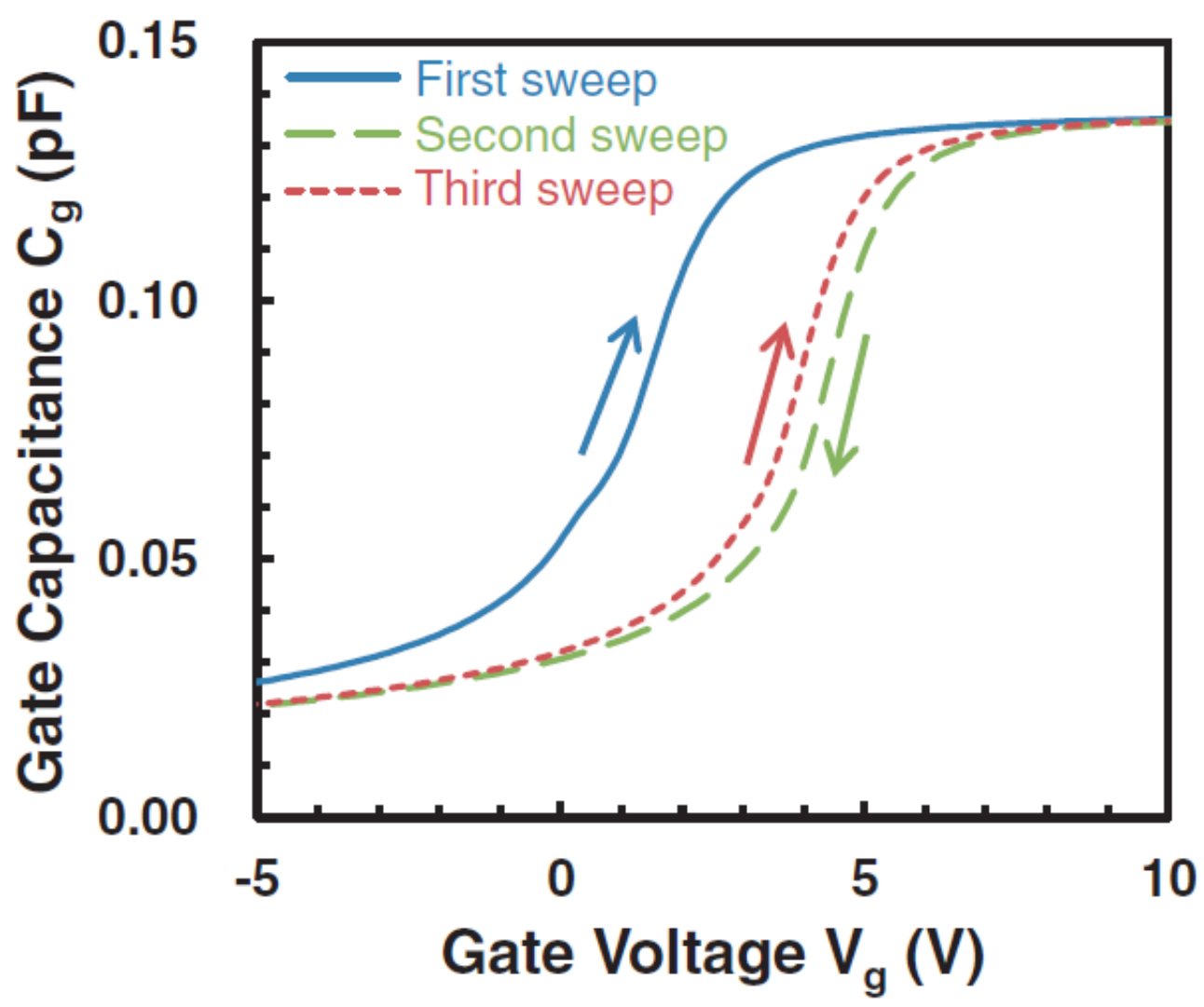

Fig. 7 


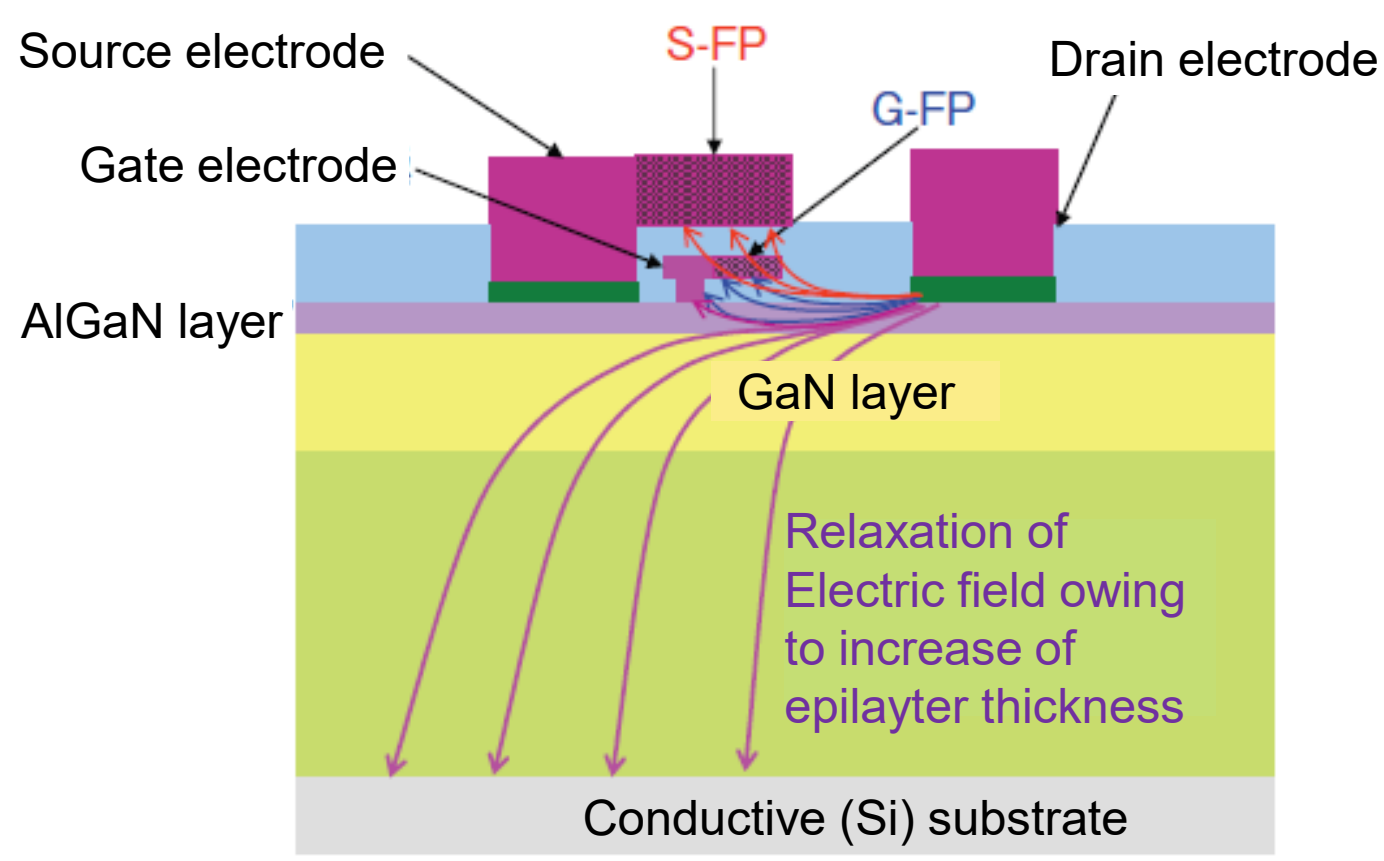

Fig. 8 
Normally-on device

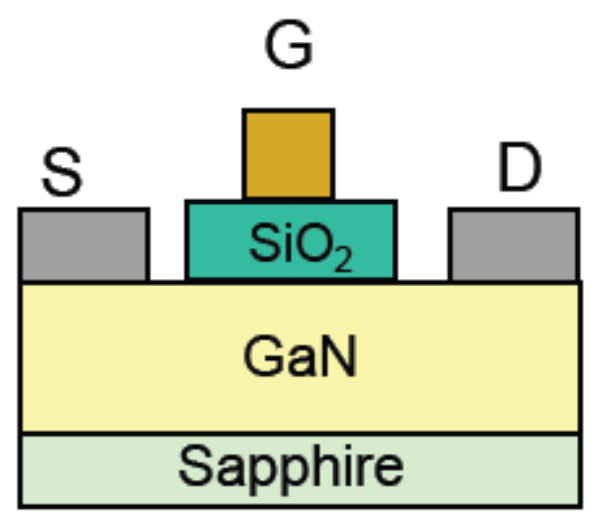

(c) Depletion from bottom p-GaN

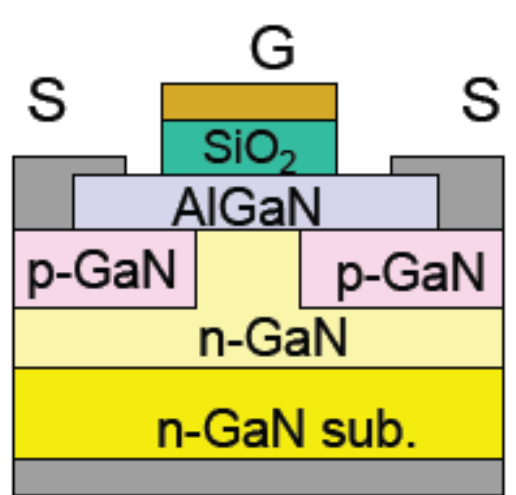

D (a) Introduction of F atoms

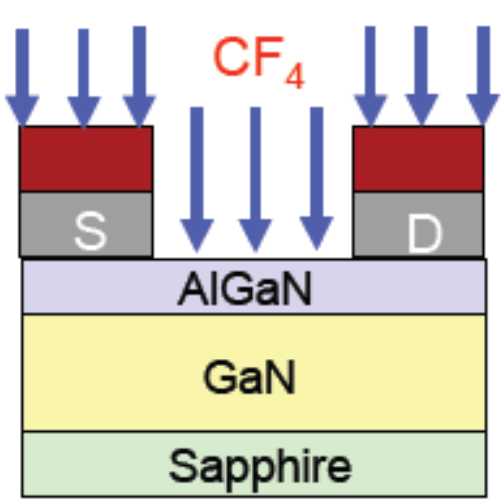

(d) Depletion from top p-GaN

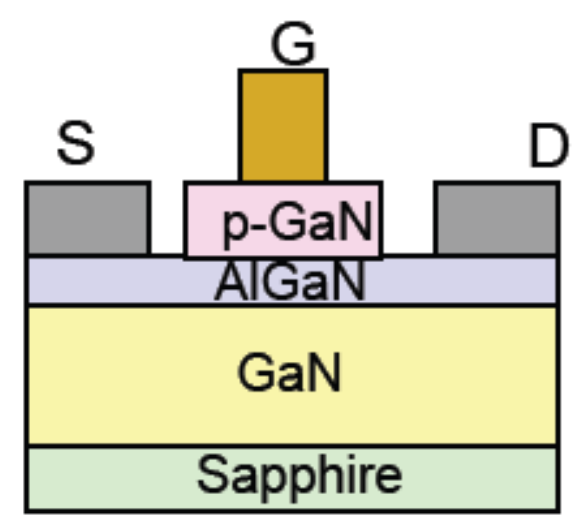

(b) Recessed and doublehetero structure

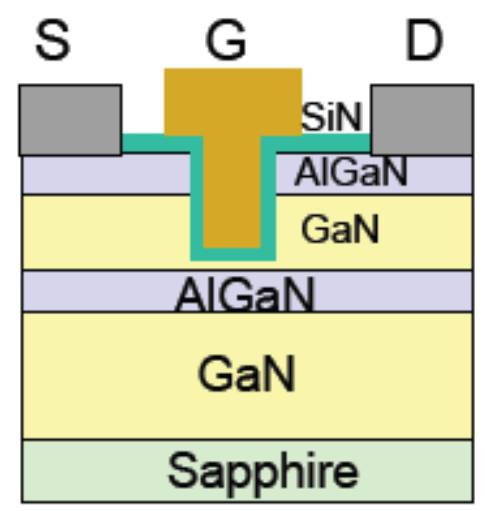

(e) Non-polar AIGaN/GaN

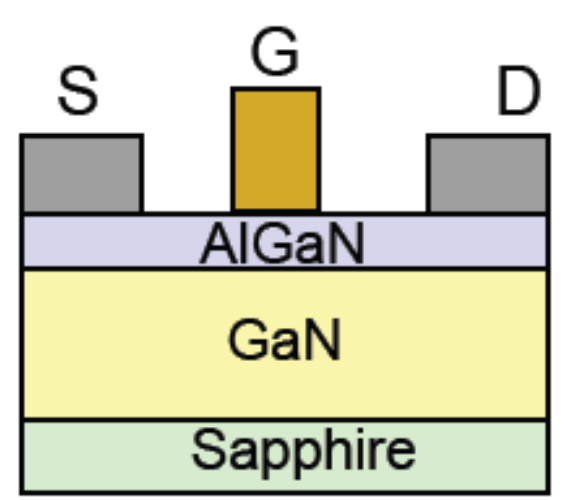

Fig. 9 


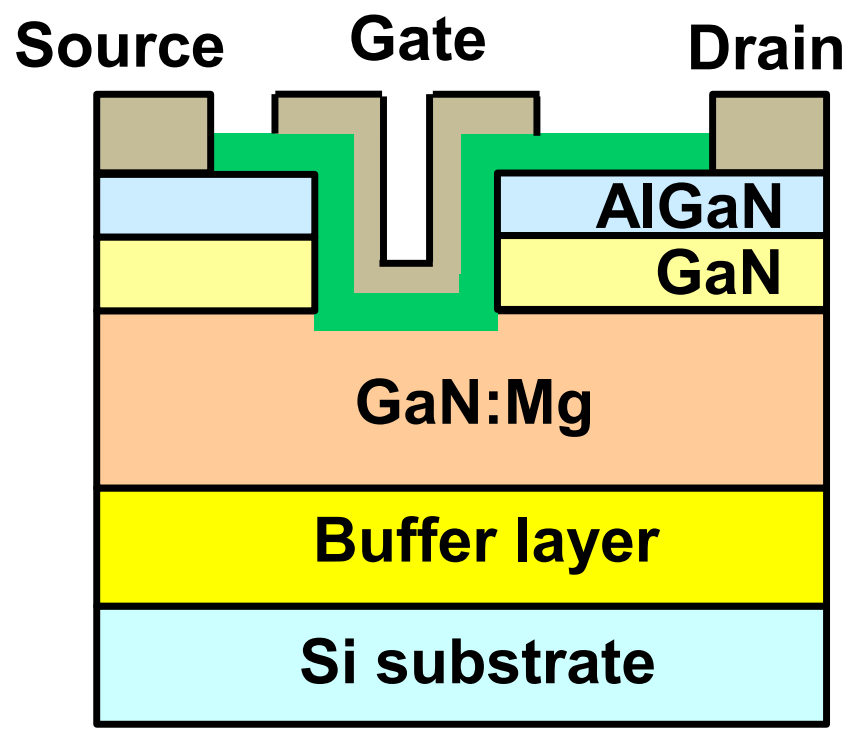

(a) MOS-HFET

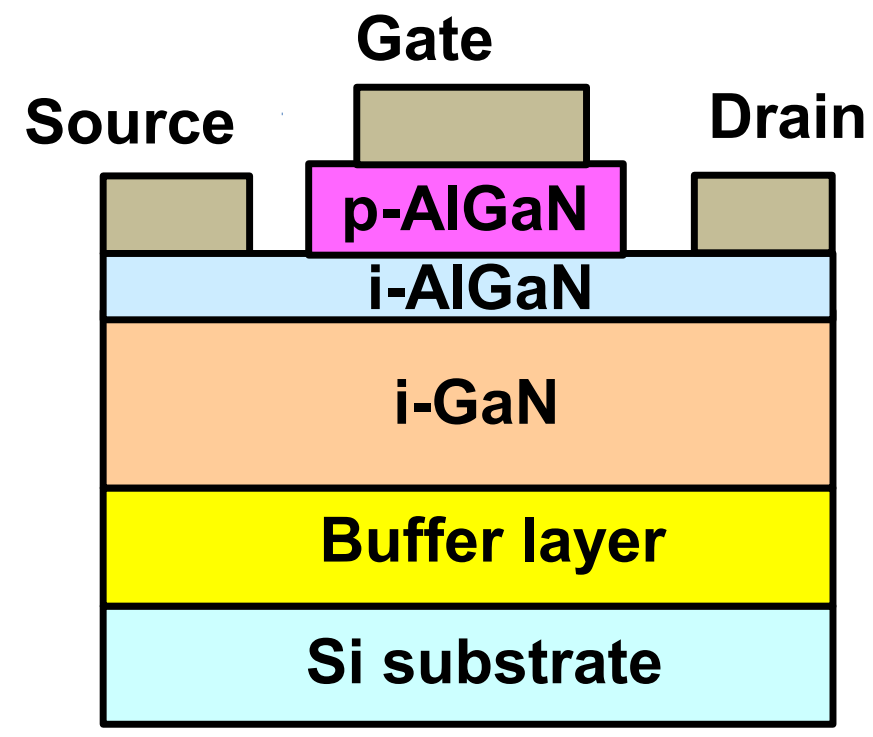

(b) GIT

Fig. 10 